University of Nebraska - Lincoln

DigitalCommons@University of Nebraska - Lincoln

Biochemistry -- Faculty Publications

Biochemistry, Department of

2009

Functional Aspects of the Hyaluronan and Chondroitin Sulfate Receptors

Ed Harris

University of Nebraska - Lincoln, eharris5@unl.edu

Paul H. Weigel

University of Oklahoma Health Sciences Center, paul-weigel@ouhsc.edu

Follow this and additional works at: https://digitalcommons.unl.edu/biochemfacpub

Part of the Biochemistry, Biophysics, and Structural Biology Commons

Harris, Ed and Weigel, Paul H., "Functional Aspects of the Hyaluronan and Chondroitin Sulfate Receptors" (2009). Biochemistry -- Faculty Publications. 67.

https://digitalcommons.unl.edu/biochemfacpub/67

This Article is brought to you for free and open access by the Biochemistry, Department of at DigitalCommons@University of Nebraska - Lincoln. It has been accepted for inclusion in Biochemistry -- Faculty Publications by an authorized administrator of DigitalCommons@University of Nebraska - Lincoln. 
Published (as Chapter 12) in Animal Lectins: A Functional View, edited by Gerardo R. Vasta \& Hafiz Ahmed (Boca Raton: CRC Press, 2009), pp. 171-192. Copyright (C) 2009 Taylor \& Francis Group LLC. Used by permission.

\title{
Functional Aspects of the Hyaluronan and Chondroitin Sulfate Receptors
}

\author{
Edward N. Harris and Paul H. Weigel
}

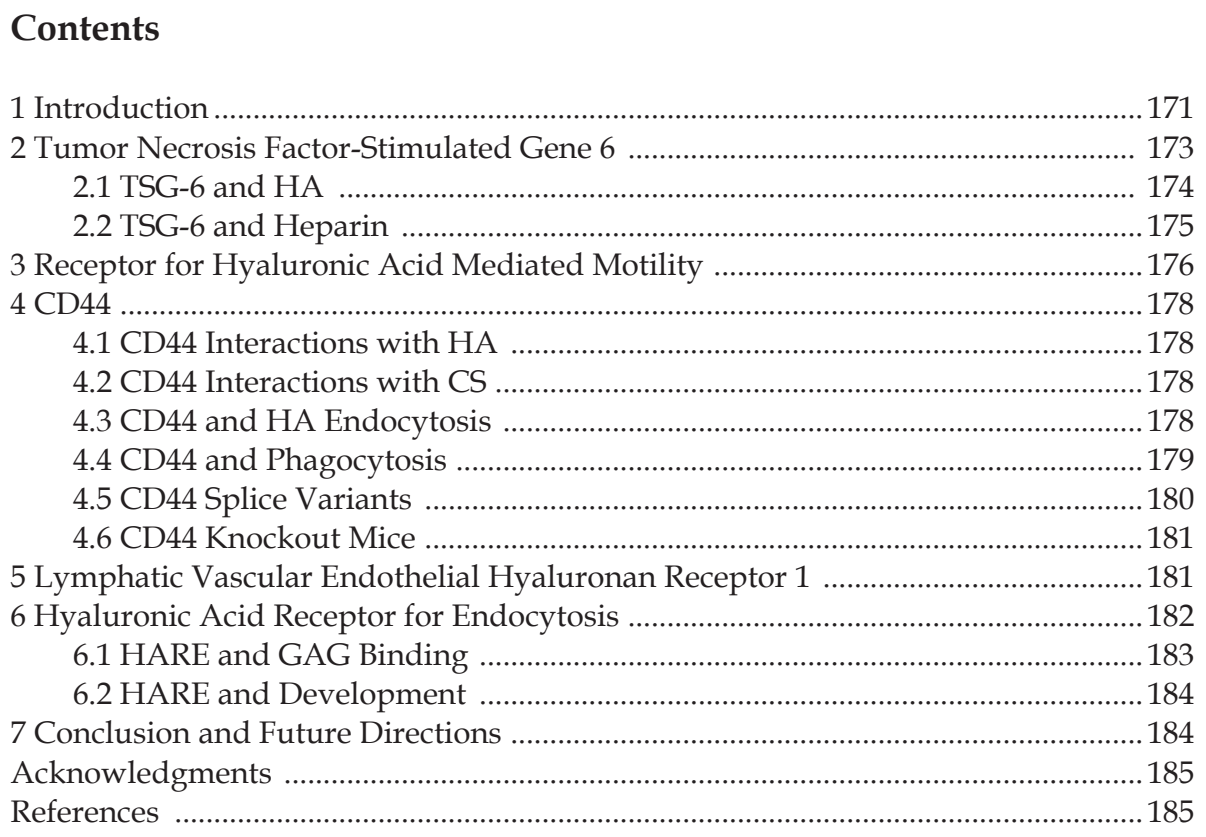

\section{Introduction}

Glycosaminoglycans (GAGs) are distinct from other sugars/oligosaccharides in that they are polymers of disaccharide units (Figure 1) composed of an amino sugar, $N$-acetylglucosamine (GlcNAc), or N-acetylgalactosamine (GalNAc), and uronic acid, glucuronic acid (GlcUA), or iduronic acid (IdUA). The exception is keratan sulfate (KS) in which the uronic acid is replaced by the neutral sugar galactose. Initially, GAGs were thought to be just part of an extracellular glue or ground substance that held tissues together and provided a liquid-like space between cells for the transport of nutrients. However, research using new technologies and techniques over the last two decades has revealed that the effects of GAGs on cells are more dynamic than previously thought. In addition to their structural roles, GAGs are fundamentally important as modifiers of cell behaviors that range from leukocyte recruitment during inflammation to the complex signaling events that help cancer cells survive during homing and metastasis. Cellular behaviors and responses depend in part on 


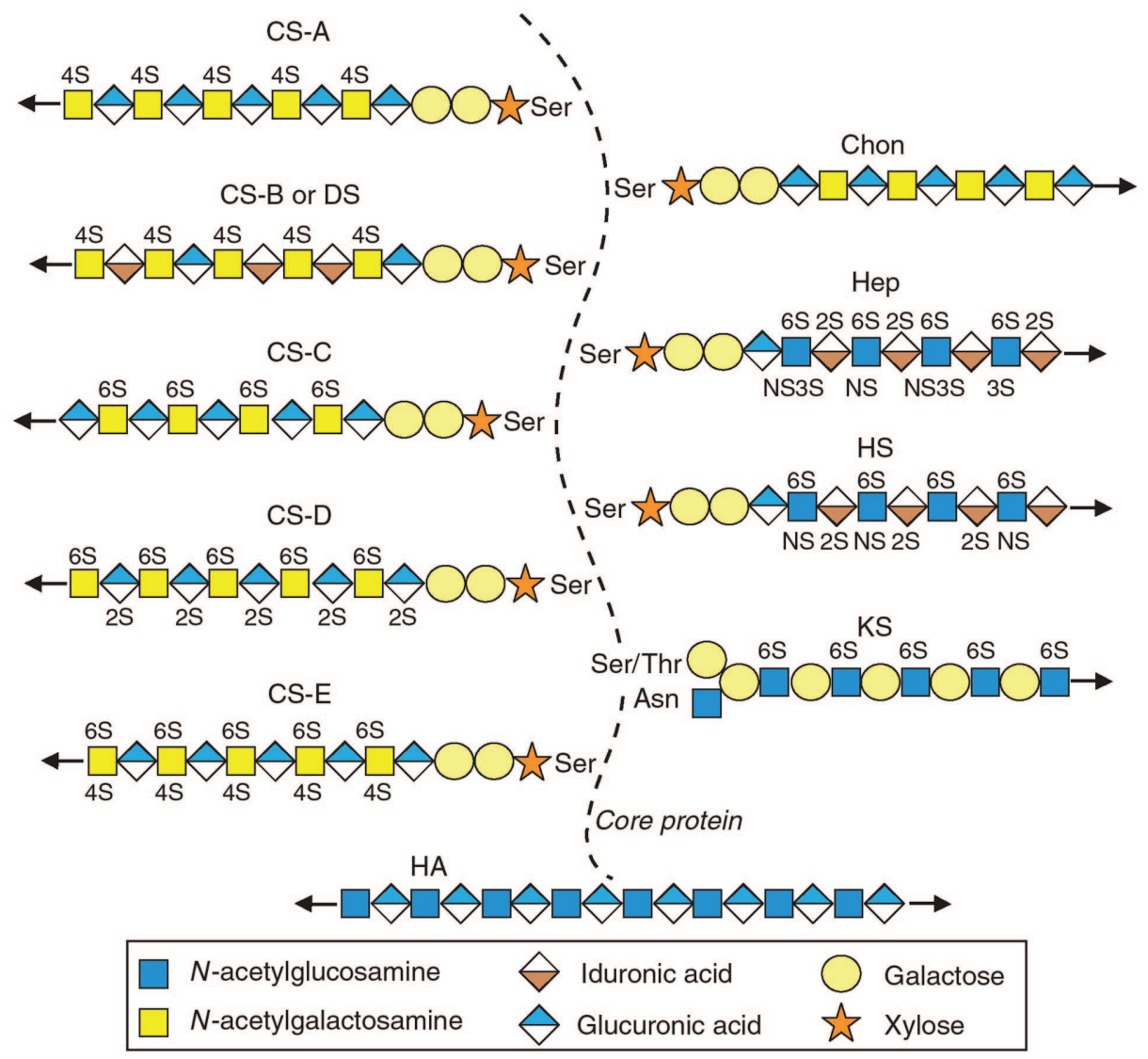

Figure 1. Schematic structures of the glycosaminoglycans. The GAGs are primarily polymers of disaccharide units containing the indicated amino and acidic sugars. Standard symbols for the sugar residues are used as defined by the Consortium for Functional Glycomics at http://grtc.ucsd.edu/essentials.html. All GAGs, with the exception of HA, are covalently linked to a variety of the $\sim 40$ known core proteins. The GAGs are attached via Ser residues, except for KS, which can also be linked via Thr or, less commonly, Asn residues. The arrows indicate that the repeating disaccharides continue to create larger polysaccharide chains.

chain length of the GAG as well as GAG-sugar modifications such as sulfation and acetylation. Longer GAGs tend to be part of the extracellular matrix (ECM) in which long cable-like structures and networks may support tissue structure through cross-linking with other ECM components. Shorter GAGs or small oligosaccharides of less than 30-50 sugars may interact with cellular receptors to promote cell signaling involving antiapoptosis or immunostimulation [1].

There are four classes of GAGs (Figure 1): Chondroitin (Chon) sulfate (CS) A through E, heparin (HP) and heparan sulfate (HS), KS, and hyaluronan (HA). CS is a polymer of the disaccharide GlcUA- $\beta 1$, 3-GalNAc- $\beta 1,4$ that can be sulfated at one or more positions: GalNAc-4 (type A), GalNAc-4 (type B), GalNAc-6 (type C), GalNAc-6, GlcUA-2 (type D), and GalNAc-4, 6 (type E). CS-B, which is now called dermatan sulfate (DS), is an unusual CS family member in which iduronic acid substitutes for some, but not all, glucuronic acid (as in HP and HS) and GlcUA is in an alpha-1, 3 linkage with GlcNAc. HP and HS are polymers of the disaccharide $\beta 1,4-G l c U A-\beta 1,4-G l c N A c$, in which some of the glucuronic acid is converted to iduronic acid. HS differs from HP in that the $N$ acetylglucosamine is de- $N$-acetylated and $N$-sulfated at position 2 . HP is typically more highly sulfated than HS and is primarily found in mast cells of the immune system. In contrast, HS is ubiquitous throughout the body and its sugars are highly sulfated in patches along the chain, allowing differing ligands to bind to regions of higher or lower anionic charge density. Although KS does not 


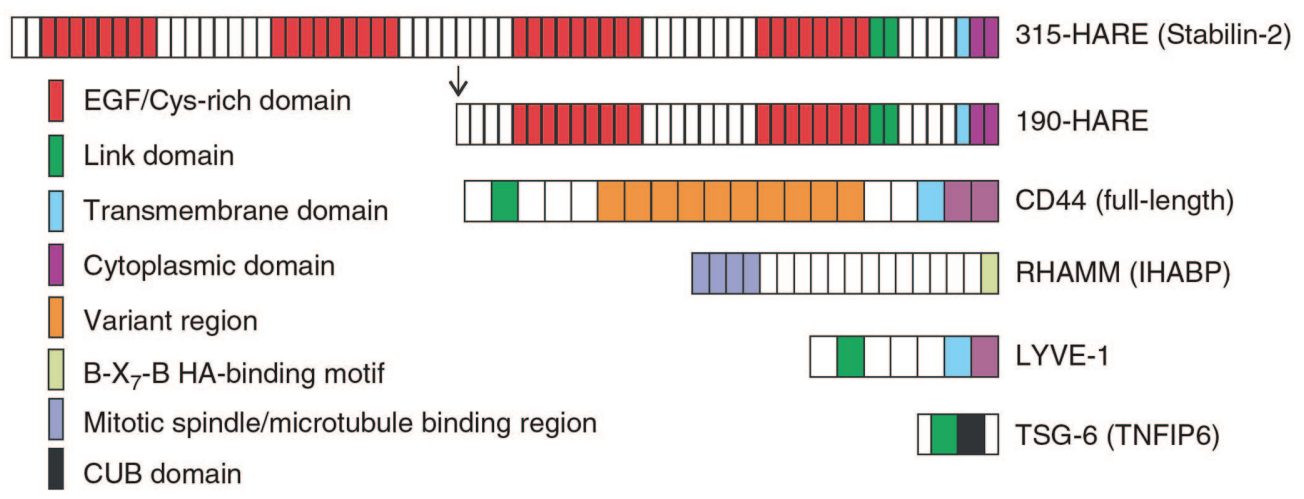

Figure 2. HA-binding receptors/proteins. The domain organizations of the five HA-binding receptors or proteins discussed in this chapter are illustrated. The arrow indicates the proteolytic cleavage of the $315 \mathrm{kDa}$ HARE to produce the smaller $190 \mathrm{kDa}$ HARE isoform. Except for TSG-6, each colored segment represents exons encoding the indicated type of protein domain that is translated from the human gene. The colored segments for TSG-6 represent protein domains.

contain uronic acid, it is grouped with the family of GAGs because of its repeating disaccharide containing GlcNAc. It is assembled on a core protein with either an O-linkage to serine (Ser) or threonine (Thr) or an N-linkage to asparagine (Asn) [2]. KS is a major component of lumican and keratocan, proteoglycans that are important in the clarity of corneal matrix [3] as well as aggrecan, a structural molecule in cartilage and during brain development [4].

Unlike the other GAGs, HA is a "free" polysaccharide that is not assembled covalently onto a proteoglycan core protein in the normal biosynthetic organelles (Golgi and ER), but is often bound to proteins after its extrusion from the plasma membrane by HA synthase. After it is released by the synthase, HA is never sulfated, de- $N$-acetylated, or modified in any way (except by I $\alpha$ as described below). All of the GAGs, except HA and some KS chains (as noted above), are attached to and assembled as O-linked glycans on proteoglycan core proteins and are sulfated to various degrees. CS, HP, and HS are attached to proteoglycans via Ser, or sometimes Thr residues, and their assembly starts with the common tetrasaccharide: $\operatorname{GlcUA}(\beta 1,3) \operatorname{Gal}(\beta 1,3) \operatorname{Gal}(\beta 1,4) X y l(\beta 1) \rightarrow$ Ser.

CS, HP, and HS often act as concomitant molecular signatures for their respective proteoglycans. Receptors or binding proteins for the GAGs can be grouped into three different classes. Receptors in the first class are soluble proteins that are ECM organizers, such as versican, aggrecan, and neurocan. The second class of receptors (e.g., CD44, RHAMM, and TSG6) is associated with cell-mediated processes stimulated by GAGs such as inflammation and cellular motility. The third class of receptors (e.g., CD44, HARE/Stabilin-2) is involved in GAG scavenging and turnover and is responsible for proper homeostasis of GAG levels in the plasma, tissues, and lymphatic fluids (Figure 2). CD44 is in two classes due its functional diversity.

\section{Tumor Necrosis Factor-Stimulated Gene 6}

Tumor necrosis factor-stimulated gene 6 (TSG-6), which was formerly named tumor necrosis factor-induced protein-6 (TNFIP6), is a multi-GAG-binding protein that is secreted during inflammation in response to chemokines such as IL-1 $\beta$, TNF, and PGE 2 . TSG-6 is a serum protein with little or no expression under normal conditions, but is quickly secreted in response to inflammatory triggers, e.g., during ovulation and arthritis. This $35 \mathrm{kDa}$ protein contains one CUB domain (complement protein subcomponents $\mathrm{C} 1 \mathrm{r} / \mathrm{C} 1 \mathrm{~s}$, urchin embryonic growth factor, and bone morphogenic protein), and one Link domain and binds a variety of GAGs, including HA [5], CS-A [6], Hep/HS [7], and DS [8]. In addition to binding these GAGs, TSG-6 downregulates the inflammatory process by binding 


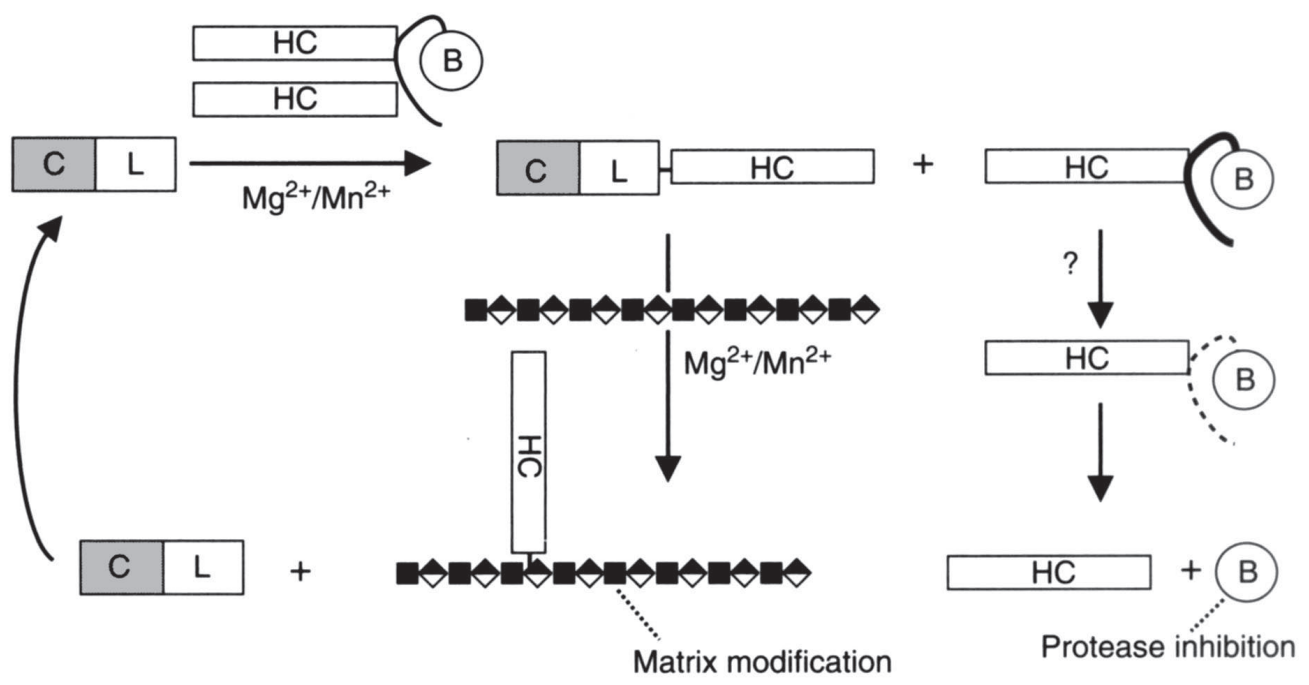

Figure 3. HA modification by the heavy chain of inter- $\alpha$-trypsin inhibitor. $\mathrm{I} \alpha \mathrm{I}$ is a three-member proteoglycan that contains two protein heavy chains (HC in boxes), the metalloprotease inhibitor bikunin (B in the circles), and a single CS-A chain (solid line). The two HC chains are linked to CS-A by ester linkages at their C-terminal aspartate residues. The Cub ( $\mathrm{C}$ in gray boxes) and Link ( $\mathrm{L}$ in white box) domains are indicated for TSG-6. TSG-6 acts as a catalyst that transfers one of the heavy chains from I $\alpha$ I to HA (alternating squares and diamonds as in Figure 1) in two steps via transesterification reactions. The first reaction results in transfer of one HC chain from I $\alpha$ I to TSG-6, forming a covalent linkage between the HC C-terminal Asp and TSG-6. The second reaction then transfers the HC C-terminal Asp to a C-6 hydroxyl group of an internal GlcNAc residue in HA [25]. The HA-HC complex is utilized for matrix substrates while the TSG-6 can be reutilized for another HC transfer reaction. The CS-A chain of the modified I $\alpha$ I is degraded by an unknown mechanism (dashed line) that liberates bikunin, which can then inhibit metalloproteases.

to multiple proteins, such as the G1 domain of aggrecan [9], interalpha-(trypsin)-inhibitor (IaI) [10], pre-alpha-(trypsin)-inhibitor (PoI) [11], pentraxin-3 [12], and thrombospondin-1 (TSP-1) [13].

The role of HA in inflammatory processes such as wound healing and ovulation is well known. Ovulation begins when ovarian cells respond to a spike in luteinizing hormone (LH), which initiates a signaling cascade involving cAMP and $\mathrm{PGE}_{2}$ mediators [14]. Granulosa and cumulus cells of the oocyte respond to these signal mediators by initiating transcription of a host of genes, one of which is TSG-6 [15-17]. TSG-6 also promotes cervical ripening by human cervical smooth muscle cells [18]. TSG-6 may be part of a network of factors that promote fertility by remodeling the ECM of the cumulus cell-oocyte complex, a matrix rich in HA [19]. TSG-6 knockout mice are subfertile or completely infertile [20]. Upregulation of TSG-6 is also most prominent in areas of chronic inflammation, such as the inflamed synovial tissues of rheumatoid arthritis patients [21] and the smooth muscles of the brochia in asthmatic patients [22].

\subsection{TSG-6 and HA}

$\mathrm{I} \alpha \mathrm{I}$ is a unique proteoglycan in which the bikunin moiety, containing two Kunitz domains with antiprotease activity, is covalently linked to two protein heavy chains (HC1 and HC2) via its CS-A chain (Figure 3). CS-A is connected to bikunin by the standard GlcUAGalGalXyl-protein linkage at Ser-10. The C-terminal Asp648 alpha-carboxyl of each HC is esterified to the C-6 hydroxyl of an internal GalNAc of the CS-A chain [23]. During the inflammatory process, TSG-6 interacts with the HCs of I $\alpha$ and mediates a reaction in which TSG-6 displaces CS-A and becomes attached to the C-terminal aspartic acid of $\mathrm{HC} 1$ or HC2 $[24,25]$. This reaction promotes transesterification of the HC from IaI, giving rise to two intermediate complexes, TSG-6-HC1 or TSG-6-HC2, in addition to the remaining substrate bi- 
kunin-HC1 or bikunin-HC2 [26]. During the inflammatory process, bikunin and the single HC linked to CS-A are cleaved by an unknown mechanism to produce free bikunin and HC. TSG-6 is recycled to its free state when it acts as a cofactor and catalyst to transfer HC to produce a covalent HC-HA complex, also called serum-derived HA-associated protein (SHAP) [27]. The HC undergoes a $\mathrm{Mg}^{2+}-$ or $\mathrm{Mn}^{2+}$-dependent transesterification reaction between TSG-6 and a GlcUA of HA [25]. The end result is that as the HCs of I $\alpha$ are transferred and sequestered by TSG- 6 and HA. Bikunin, in its monomeric form, is the protease inhibitor neutralizing plasmin-induced metalloprotease activity [26].

It is the plasmin-induced metalloprotease activities involving leukocyte recruitment and the release of inflammatory cytokines (TNF- $\alpha$, IL-1, IL-17, LPS, TGF- $\beta$, and PGE 2 ) that cause the red and swollen features of inflamed tissues. In the case of ovulation, a condition that mimics inflammation, cumulus cell ECM remodeling is dependent on TSG-6 and I $\alpha$ I or P $\alpha$ I activities to expand HA-rich matrix assembly [28]. P $\alpha \mathrm{I}$ is an ortholog of I $\alpha$ I containing just one HC (HC3) connected to bikunin via CS-A [29]. The model for TSG-6 interaction with P $\alpha$ I is similar to the I $\alpha$ I-TSG-6 model, in which TSG-6 acts a catalyst to transfer HC3 to HA [20].

The HA-binding groove of TSG-6 is the best characterized of any of the HA-binding receptors. The amino acids essential for HA binding were first identified by site-directed mutagenesis [30] and then confirmed by nuclear magnetic resonance (NMR) spectroscopy [7]. Key contact residues in the HA-binding groove are $\mathrm{Lys}^{11}, \mathrm{Tyr}^{12}, \mathrm{Tyr}^{59}, \mathrm{Phe}^{70}, \mathrm{Tyr}^{78}$, and $\mathrm{Arg}^{81}$. Due to the high content of aromatic residues, it is likely that the hydrophobic face of pyranoside rings in HA stack onto the aromatic side chains of the amino acids that form two hydrophobic pockets. In addition, $\mathrm{Cys}^{47}, \mathrm{Val}^{57}$, $\mathrm{Ile}^{61}, \mathrm{Cys}^{68}$, and $\operatorname{Trp}^{88}$ are also likely candidates to interact closely with an HA chain. Computer modeling of the binding pocket reveals that five sugar rings of HA are required to fill the binding groove and that the hydrophobic pockets accommodate the acetamido side chain of GlcNAc [7]. Other cellular HA receptors and HA-binding proteins with Link domains also fit this model with some degrees of variation.

\subsection{TSG-6 and Heparin}

An increase in plasmin activity is associated with ECM reorganization during inflammation, such as occurs in rheumatoid arthritis [31], multiple sclerosis [32], bacterial infection [33], tumorigenesis/ angiogenesis [34], and even follicle rupture during ovulation [35]. Plasmin activity induces the liberation of inflammatory cytokines, as well as activating matrix metalloproteases. TSG-6 is one of several molecules that regulate the antiplasmin activity or chondroprotective responses, through I I and $\mathrm{PaI}$, to prevent inflammation-mediated damage to the host. HP, in addition to the more heterogeneous HS, also binds TSG-6 and I $\alpha$ I and is a regulator of serine proteases through its inhibitory activity. Using mutagenesis and NMR spectroscopy, Mahoney et al. discovered that HP binds to TSG-6 at a distinct site from HA [36]. The amino acids involved are $\mathrm{Lys}^{20}, \mathrm{Lys}^{34}$, $\mathrm{Lys}^{41}$, and Lys ${ }^{54}$. Although HP does not affect HA-TSG-6 binding, HA and HP cannot both bind to TSG-6 at the same time, indicating that when bound to either GAG, TSG-6 is locked into a conformation that precludes binding to the other GAG. In addition, HP is a strong competitor for CS-A binding, suggesting that CS-A and HP bind at the same site. HP-TSG-6 binding was most optimal at $\mathrm{pH} 6$ and binding affinities dropped when the $\mathrm{pH}$ shifted in either direction [36]. A lower $\mathrm{pH}$ reflects the conditions at sites of inflammation, indicating that HP-TSG-6 complexes could have increased antiplasmin activity. In contrast, $\mathrm{pH}$ changes had no effect on HA-TSG-6 binding. It is not clear how both HA and HP modulate the antiplasmin activity of TSG-6, but the current model requires dimerization of TSG-6 [36]. To further potentiate the antiplasmin activity of bikunin, two TSG-6 proteins may dimerize when bound to a single HP or HS chain (much like a sandwich) and the TSG-6 dimers are able to bind to bikunin. This binding may change the orientation of the Kunitz domains of bikunin making them more accessible, thus increasing their antiplasmin activity [36]. 
To make this story a bit more complex, but perhaps at the same time more reasonable, TSG-6 also interacts with TSP1. TSP1 directly inhibits T-cell mediated T-cell activation [37] and dendritic cell activation [38], but promotes neutrophil oxidative burst responses [39]. TSP1 is one of many factors involved in early wound repair and mice lacking an effective TSP1 response are delayed in wound healing [40]. The N-terminal module of TSP1 is related to the TSG-6-binding pentraxin family of proteins and binds TSG-6 in a divalent cation-dependent manner. The N-terminal module of TSP1 also binds HP and is an effective inhibitor of the TSP1 interaction with TSG-6. TSP1 and HA do not bind with each other but both bind to TSG-6 at distinct sites. Furthermore, in the absence of HA, TSP1 enhances the interaction of TSG- 6 with I $\alpha$ I, resulting in an increased degradation of I $\alpha$ I. In summary, a trimolecular complex consisting of TSP1-HA-TSG-6 acts upon I $\alpha$ I to give rise to HA-HC complexes for ECM remodeling. The presence of HP or HS may negatively regulate this activity [13]. Overall, both HA and HP or HS proteoglycans enhance the antiplasmin activities of TSG-6 and concomitant effectors during inflammation.

\section{Receptor for Hyaluronic Acid Mediated Motility}

Receptor for hyaluronic acid mediated motility (RHAMM) is present as both a plasma membrane GPI-anchored HA receptor and an intracellular HA-binding protein lacking both transmembrane and cytoplasmic signal sequences [41]. Consequently, it is also called intracellular hyaluronic acidbinding protein (IHABP) or CD168. RHAMM was first identified, with the use of anti-RHAMM antibodies, in murine 3T3 cells as a group of HA-binding proteins with molecular masses of 56, 66, and $70 \mathrm{kDa}[42,43]$. Following this initial discovery, the masses reported for RHAMM have been quite variable, ranging from $58 \mathrm{kDa}$ on human B cells [44] to $120 \mathrm{kDa}$ in fibroblasts from src null mice [45], based on immunoreactivity against anti-RHAMM antibodies. The wide variety of molecular masses could be due to proteolysis, different glycosylation states of the receptor [46], or the presence of splice variants [47]. The full-length human RHAMM, which is about $85 \%$ homologous to murine RHAMM, is identified as a 725-amino acid protein that migrates at $\sim 84 \mathrm{kDa}$ by sodium dodecyi sulfate polyacrylamide gel electrophoresis (SDS-PAGE).

RHAMM is the founding member of hyaladherins (HA-binding proteins) that contain the basic $\mathrm{B}-\mathrm{X}_{7}-\mathrm{B}$ motif, in which any seven amino acids are flanked by two basic amino acids, either lysine or arginine. RHAMM contains two of these motifs near the C-terminus that mediate high-affinity protein binding to HA $\left(K_{d}=10^{-8} \mathrm{M}\right)[43,48]$. Mutagenesis of any basic residue flanking the B- $\mathrm{X}_{7}-\mathrm{B}$ motifs led to a sharp decrease in HA binding [49]. Multidimensional NMR analysis of domains containing the $\mathrm{B}-\mathrm{X}_{7}-\mathrm{B}$ HA-binding motifs reveals that it is a helix-loop-helix with a coiled-coil tertiary structure, which is very different than the architecture of the Link domains found in most other HA-binding proteins $[5,50]$. RHAMM is a predominantly helical protein containing more basic residues than any of the other hyaladherins. Theoretically, the net positive charge of the protein could allow it to bind to any GAG due to the high negative charge densities of sulfates of the CS and HS families. However, none of the CS family members bind to RHAMM. Other than HA, only HP binds to RHAMM and competes with HA at the same binding sites. In ras-transformed cells, HP induces cell locomotion in a dose-dependent manner. Biotinylated HP specifically binds to GST-RHAMM and deletion of the two $B-X_{7}-B$ motifs negates $\mathrm{HP}$ binding [49]. In contrast, other groups dispute the claim that HP binds to RHAMM, although all agree that HA binds to RHAMM with high affinity [51, 52]. It is still unclear if HP specifically binds to RHAMM because different experimental methodologies and GAG sources were employed for determining HP-RHAMM binding, and few follow-up studies have appeared after the HP-RHAMM "controversy" between 1994 and 1998.

Expression of RHAMM is widespread in a variety of cell types including smooth muscles cells $[53,54]$, and endothelial cells [55]. In addition, overexpression of full-length RHAMM and some of its splice variants are found in cancers of the hematopoietic system [56,57], breast [58, 59], pancreas 
[60], brain [61], and the lower GI tract [62]. RHAMM is primarily located in the cytoplasm within cells, hence the alternative name IHABP, but depending on cell type, it can also be expressed on the cell surface where it interacts with focal adhesion sites [63].

In the cytoplasm, RHAMM binds intracellular HA and localizes to both microtubules [54] and centrosomes, and participates in the maintenance of spindle pole integrity. The function of intracellular HA is unknown, but it is thought to be important during cytokinesis and for cellular movement; how HA functions in these capacities is not clear. Most hypotheses for functions of intracellular HA point to the hyaladherin (HA binding) activity of RHAMM and thus a role for intracellular RHAMM-HA interactions. There is still considerable debate on the source of intracellular HA since the three human (and other mammalian) isozymes of HA synthase (HAS) are plasma membrane enzymes whose only characterized activity is the extrusion of HA into the ECM [64]. Previous reports suggest that intracellular HA is a diffuse network of cable-connecting vesicles, which becomes more pronounced with serum stimulation or during mitosis at the G2/M phase [65]. In keratinocytes, extracellular HA is internalized in a novel endocytic pathway involving CD44 that is independent of clathrin-coated pits [66]. It is known that some, but not all internalized, HA is catabolized down to monosaccharides and simple organic molecules. The proposed HA-rich, nonacidic vesicles (hyaluronasomes), which would also contain hyaluronidases, are specialized structures that may, theoretically, be a source of intracellular HA that interact with microtubules and motor proteins to facilitate cytokinesis [54,67]. Despite several similar models in the literature, the hyaluronasome is still a hypothetical structure that has not been biochemically identified, isolated, or characterized.

RHAMM is a linker protein connecting microtubules via its N-terminus [68] and HA cables via its C-terminus [49]. More specifically, the C-terminus of RHAMM also contains a leucine zipper domain, essential for binding with dynein- and kinesin-like protein 2 (TPX2), which partially overlaps the HA-binding motifs [69]. RHAMM binds directly to TPX2 in a cell cycle-dependent manner, is essential for spindle pole assembly and maintenance throughout the cell cycle, and is required for cell progression through $\mathrm{G}_{2}$ of mitosis [70]. The RHAMM interaction with microtubule motors may explain the role of HA in mitotic regulation and why increased RHAMM expression might enhance the oncogenic properties of cells, which is common in several cancer types including multiple myeloma [69], breast [59], stomach [71], and endometrial [72].

Multiple studies over the last several decades provide a connection between cell motility and HA [73-77]. One such study, comparing metastases and primary tumor staining, found that RHAMM expression was significantly higher in the metastatic cells. Presentation of RHAMM on the cell surface, where it can interact with external HA, can regulate signaling downstream of ras through ERK, the extracellular signal-regulated protein kinase [59] and through Src kinases [45]. Treatment of cells with nanogram amounts of HA promoted changes in downstream events such as phosphorylation and dephosphorylation of focal adhesion kinase, pp125FAK. This rapid and transient phosphorylation was regulated in part by RHAMM signal transduction via MAP kinases ERK-1/2 [63, 78]. The interaction of ERK and RHAMM stimulates RHAMM binding to cytoskeletal elements that induce cellular locomotion $[68,79]$.

The human gene encoding RHAMM is located on chromosome $5 q 33.2$ and contains 18 exons, which therefore makes it a likely candidate for alternative splicing [80]. Likewise, the mouse gene contains 14 exons and Western analyses of fibroblast cell lysates revealed two bands, a major $70 \mathrm{kDa}$ band and a minor larger $73 \mathrm{kDa}$ band encoding exon 4 [41]. An analysis of both breast and cervical cancers versus normal tissue revealed the expression of RHAMM splice variants lacking sequences encoded by only exon 4, only exon 13, and both exons 4 and 13, suggesting that increased expression of RHAMM-like splice variants contribute to an oncogenic phenotype [51, 68]. B cells and plasma cells taken from multiple myeloma patients showed two deletion splice variants of RHAMM lacking $48\left(\right.$ RHAMM $\left.^{-48}\right)$ or 147 DNA base pairs (RHAMM $\left.{ }^{-147}\right)$, which were expressed in the cancerous cells but not in normal or resting B cells [47]. Increased expression of both the full-length and variant RHAMM proteins alters normal intracellular signaling pathways, inducing the oncogenic phenotype. 


\section{$4 \mathrm{CD} 44$}

Human CD44, first known as a lymphocyte homing receptor, is a C-type lectin plasma membrane receptor that binds to HA and other ECM components, and plays major roles in cytokinesis, endocytosis, phagocytosis, cell signaling, and ligand intemalization. The common or standard CD44 receptor is encoded by exons 1-5, 16-18, and 20, which together produce an $\sim 80 \mathrm{kDa}$ protein. Exons 6-15 are highly variable exons, commonly named v1-10, whose multiple combinations produce many CD44 variants that contribute to its wide array of receptor activities [81]. For example, CD44v6 expresses exon 6 of the variable group, which is really exon 11 if counting from exon 1.

\subsection{CD44 Interactions with HA}

CD44 binds HA via the Link domain encoded by exon 2. This Link domain, which is well conserved and similar to the Link domains found in other hyaladherins, is 100 amino acids long, has two antiparallel $\beta$-sheets crossed over by two $\alpha$-helices, and is held together by two disulfide bridges [82]. The receptor on resting leukocytes does not bind HA until it is "activated" by proinflammatory cytokines, which results in the modification of the N-glycans on CD44 [83]. It is thought that tumor necrosis factor-alpha (TNF- $\alpha$ ) induces sialidase activity to remove sialic acid from the N-glycans, which then allows HA-binding to the receptor [84]. The critical residues involved with HA binding include $\mathrm{Arg}^{41}, \mathrm{Tyr}^{42}, \mathrm{Arg}^{78}, \mathrm{Tyr}^{79}$, along with the other necessary residues, which are $\mathrm{Lys}^{38}{ }^{2} \mathrm{Lys}^{68}$, Asn $^{100}$, Asn ${ }^{101}$, and $\mathrm{Tyr}^{105}[82]$.

\subsection{CD44 Interactions with CS}

The CD44 Link domain interacts with the CS family of GAGs. In a competition assay, versican binding to CD44 was inhibited by HA, Chon, CS-A, CS-B, CS-C, CS-D, and CS-E, but not by HS or KS. In a complementary biochemical assay, soluble CD44 also directly bound all these immobilized GAGs with the exception of KS and HS [85]. In a rolling cell experiment, murine leukocytes expressing CD44 initially bound and rolled on capillary tubes coated with CSs at physiological flow rates. The rolling action of these cells was abrogated when either the cells were treated with anti-CD44 antibodies or the tubes were treated with chrondroitinase $\mathrm{ABC}$, but not hyaluronidase [86]. In a more relevant physiological context, one of the major proteoglycans, Serglycin, is a ligand for CD44. Serglycin (Mr 17,600; previously known as gp600) is secreted by hematopoietic cells and contains CS-A and CS-C chains attached to a centrally located Ser-Gly repeat [87]. Serglycin plays a role in the packaging and inactivation of some of the proteases in granules of neutraphil granulocytes [88]. Granzyme B, a perforin component that can disrupt cell membranes, is packaged in part by Serglycin in the maturing granule of cytotoxic T-cells [89-91]. Serglycin is secreted primarily by lymphocytes, spleenoctyes, and thymocytes in small amounts, but its secretion is greatly increased by lipopolysaccharide or concanavalin A [87]. Murine T-cells expressing CD44 aggregate in the presence of Serglycin-containing serum. Furthermore, purified Serglycin binds to CD44 via its CS-A chain, which increases CDS-dependent release of granzyme B, suggesting that this proteo-glycan may regulate lymphoid cell adherence and activation [92, 93]. Serglycin-deficient T-cells fail to package granzyme B, but not granzyme A, Fas ligand, and perforin, although the mRNA levels for all three proteins were not affected and the late-stage apoptosis of target cells mediated by these cytotoxic cells was also unaffected. In summary, these studies point out that the CS chains of Serglycin bind to the HA-binding region of the Link domain of CD44 and is important in part for the cytotoxic T-cell response in cell-mediated apoptosis and cell rolling.

\subsection{CD44 and HA Endocytosis}

CD44 is the most common endocytic receptor for HA and possibly CS at the local tissue level. Initial studies of CD44-mediated endocytosis performed in alveolar macrophages and simian virus 
transformed murine 3T3 fibroblasts suggested that CD44 is the primary endocytic receptor for HA in these cells and responsible for its delivery to lysosomes for degradation [94]. The endocytosis of HA also facilitates a higher cycling rate of CD44 on the cell surface of chondrocytes, which is blocked by anti-CD44 antibodies [95]. Chondrocytes are present in HA-rich environments where the balance of synthesis and catabolism are critical to maintain homeostasis of HA quantity and size (since chain length affects viscosity). Decreases in the mass of HA will increase its fluidity and could cause adverse cellular signaling events and, possibly, inflammation (e.g., in arthritis). Once CD44 binds HA, the complex is internalized followed by dissociation in an early endosome, most likely the recycling syntaxin13 and GTPase Rab11/25-rich endosome that promotes surface expression of ligand-free CD44 [96]. This mechanism is regarded as the "slow" recycling pathway with a half-life of about 30 min. Fast recycling regulated by Rab4 has not been shown to be associated with CD44 recycling.

The mechanisms of internalization and catabolism of HA are not the same in all tissues. Catabolic pathways for HA exist in smooth muscle cells [97], macrophages [94, 98], chondrocytes [99], and some cancer cells [100]. Roughly half of all the HA in the human body is localized in the dermal layers of the skin. Keratinocytes possess a novel, noncoated pit-mediated endocytic pathway for internalization and catabolism of HA. Epidermal keratinocytes actively produce HA, which has a short half-life of $\sim 1.5$ days, indicating that the skin is one of the most active tissues in the body for the synthesis and degradation of HA [101, 102]. Partially digested chains of high molecular mass HA [66] bound to CD44 are internalized, and trafficked to nonacidic, perinuclear vesicles from which the HA is eventually sorted to lysozymes and then degraded to monosaccharides by lysosomal hyaluronidase and the two exoglycosidases: $\beta$ - $N$-acetylglucosaminidase and $\beta$-glucuronidase. The terminal HA-degrading vesicles are devoid of Cathepsin D, normally present in lysosomes, suggesting that the HA is delivered to a specialized lysosome [66].

The route of internalization in keratinocytes is independent of clathrin-coated pit and caveolinmediated mechanisms. Consistent with this, the cytoplasmic domain of CD44 does not contain any AP-2 or clathrin consensus-binding motifs, suggesting that internalization is regulated by alternative mechanisms. Exon 20, the most 3' exon, encodes the intracellular C-terminal 70 amino acids, which contains binding sites for ankyrin and the ezrin/radixin/moesin (ERM) linker proteins of the actin-based cytoskeletal network and the intracellular signaling cues for internalization, some of which have not been elucidated $[103,104]$. CD44 is widely thought to be pivotal for HA-induced chemotaxis and movements that require cytoskeletal structures. A study with rat endothelial cells in situ showed that CD44 and the ERM proteins colocalize with each other on actin filaments near the plasma membrane and this region was also enriched with phosphorylated protein kinase $C \alpha / \beta$ II. Induction of actin branching facilitated cellular movements needed for normal wound healing. Addition of protein kinase $\mathrm{C}$ (PKC) inhibitors caused F-actin structures to disassemble and the microdomains containing CD44 and associated proteins to disassociate. The end-result of this PKC inhibition was to decrease wound healing [105]. CD44 also contains two Ser phosphorylation sites. Inhibition of casein kinase II decreased CD44 association with the actin cytoskeleton, suggesting that CD44 is activated in a phosphylation- and dephosphorylation-dependent way during cytoskeletal movement [106]. Although increased CD44 expression is thought to promote tumorigenesis, at least one of the cytoskeletal proteins belonging to the ERM family of proteins may temper this activity. The NF2 tumor suppressor gene, which encodes Merlin, induces tumorigenesis in Schwann cells through a loss-of-function mutation [107]. In cell culture, overexpression of Merlin prevents CD44 from binding with HA. Additionally, knocking down the expression of endogenous Merlin in Tr6BC1 Schwannoma cells in Rag1 mice or overexpression of a dominant-negative Merlin (missing the first 50 amino acids from the N-terminus) results in the promotion of tumor cell growth [108].

\subsection{CD44 and Phagocytosis}

The HA-binding activity of CD44 is diverse enough to include phagocytosis of apoptotic bodies. Following tissue injury and the influx and resulting apoptosis of polymorphonuclear leukocytes 
(PMN), clearance mechanisms must exist to remove cellular debris in order for normal healing to occur. The persistence of injury and the lack of healing in CD44-deficient mice demonstrate how CD44 contributes to the clearing of apoptotic cells [109]. The precise mechanism for how this occurs is still unknown. CD44 also contributes to the phagocytosis of bacteria by PMNs, further supporting the notion that ankyrin attached to CD44 assists in the maturation of phagosomes with the inclusion of lysosomal vesicles [110]. Confirming these earlier data, a more definitive study using erythrocytes coated with either anti-CD44 or control antibodies of the same isotype measured a 25-fold increase in CD44selective phagocytosis by RAW 264.7 macrophages in comparison to controls. The induction of cell signaling molecules such as Syk, Rac1, and PI3-kinase during phagocytosis indicates that CD44 is a competent phagocytic receptor, in addition to its HA endocytosis and cell matrix-binding activities [111].

\subsection{CD44 Splice Variants}

The most common isoform of CD44 is $\mathrm{CD} 44 \mathrm{H}$ ( $\mathrm{H}=$ hematopoietic), also called CD44s (s = standard), which is encoded by exons $1-5,16-18$, and 20 with a mass of $\sim 80 \mathrm{kDa}$. The extracellular domain contains a variable region encoded by exons 6-15 (also termed variants 1-10) that can increase the mass of CD44 to just above $200 \mathrm{kDa}$ and could theoretically result in thousands of different CD44 splice variant combinations. The inclusion of exon 19 in place of exon 20 is a special case, in which the resulting cytoplasmic domain consists of only three amino acids, forming a "tail-less" receptor variant or CD44st (short-tail). CD44st does not bind or internalize HA efficiently and its expression varies from $5 \%$ to $33 \%$ of total CD44 receptors in normal articular chondrocytes. Interestingly, CD44st may be a one of several regulators for $\mathrm{CD} 44 \mathrm{H}$, since antisense inhibition of CD44st enhances $\mathrm{HA}$ binding and internalization by $\mathrm{CD} 44 \mathrm{H}$ [112]. Other studies with CD44st indicate that the cytoplasmic domain of CD44 is also critical for HA binding, pericellular matrix assembly, and endocytosis of HA [113]. It is not known how CD44st interacts with $\mathrm{CD} 44 \mathrm{H}$, but one possibility is steric interference through common ECM-binding partners.

Most CD44 splice variants were discovered, with the use of reverse transcription polymerase chain reaction (RT-PCR) or immunohistochemistry in cancer specimens, as markers of metastasis $[114,115]$. The predominant hypothesis is that the increased expression of CD44 and its variants leads to increased cell motility, survival, and sometimes, proliferation of cancerous cells in many types of tissues. Hundreds of studies have explored the involvement of many variants in numerous types of cancers, so we will briefly note just a few common CD44 variants and their associated cancers. Culty et al. first discovered variants in breast cancer. Their findings indicated that not all of the higher mass species of CD44 bind HA and those that did bind HA had differing binding affinities [100]. CD44v6 and v9 splice variants are present in numerous malignant cancers. CD44v6 associates with phosphylated c-Met/hepatocyte growth factor/scatter factor and stimulates downstream signaling through the MAP kinase pathway, stimulating metastasis in colon cancer cells [116]. CD44v6 and v9 protein levels, but not mRNA levels, are also increased by osteopontin, a secreted phosphoprotein that regulates both chemotaxis and attachment, in breast cancer cells [117]. CD44v6 expression is increased in higher grades of malignancy in endometrial cancers, suggesting that this isoform is directly involved with stromal invasion of early squamous cervical carcinoma [118]. A large-scale study by Liu et al. [119] correlated metastasis of breast, gastric, lymph node, colorectal, and lung cancers with CD44v6.

Most studies have shown positive correlations between increased CD44 variant expression and disease. For example, CD44v3-10 is usually more highly expressed than normal in head and neck tumors, breast, ovarian, and general gynecological tumors [120-123]. Some studies indicate that CD44 variants may curtail the activities of CD44H. A study using SW620 cells, which do not express CD44, suggests that in this colon cancer cell model, overexpression of CD44 variants leads to a decrease in motility. When both $\mathrm{CD} 44 \mathrm{H}$ and other CD44 variants are coexpressed, these variants interfere with the normal motility functions of $\mathrm{CD} 44 \mathrm{H}$ [124]. Recently, the view is emerging that the pattern of 
CD44 splice variants appears to be more relevant to disease outcomes than the amount of individual CD44 variants. For example, normal lung and nonsmall cell lung carcinoma express CD44 v10, v810, v6-10, v2-10, and v3-10. In lung adenocarcinoma, the expression of v6-10, v2-10, and v3-10 were lower, whereas in squamous cell lung carcinoma, the expression of these five variants was either the same as normal lung or higher [125]. Certainly, the issues of CD44 splice variant expression patterns and the different ligands available for the variant region of CD44 is just beginning to be explored.

\subsection{CD44 Knockout Mice}

Since CD44 has many functions including cell-matrix interactions, internalization of HA, and transduction of cellular signaling, one would assume that animals lacking CD44 would be developmentally impaired or severely deformed. It turned out that the CD44 knockout mice show no real change in phenotype [126]. Their skeleton, cartilage, and skin dermis are quite normal. In conditional knockouts in which a CD44 antisense transgene was controlled by the cytokeratin promoter, animals overaccumulated HA within the dermis of the skin and in the cornea of the eye [127]. The results suggest that during development in the CD44-KO background, compensatory mechanisms exist to take care of local HA turnover and ECM stabilization. These compensatory mechanisms either do not exist or are overwhelmed when there is a loss of CD44 in developed cells. It is not known what receptors might compensate for loss of CD44, but there are some good candidates. RHAMM could be one of them, since it binds HA, promotes cell signaling, and leukocyte migration. In the arthritic CD44-/- mouse, signaling through the RHAMM pathway upregulates proinflammatory genes such as IL-1B, TNF $\alpha$, and MAP kinase. The paw swelling symptom of collagen-induced arthritis was partially alleviated with anti-RHAMM antibody treatment, suggesting that cell migration and ECM stabilization is mediated by RHAMM in the absence of CD44 [128]. Overall, this indicates that RHAMM is a compensatory receptor for CD44, but more research is needed to verify this.

\section{Lymphatic Vascular Endothelial Hyaluronan Receptor 1}

As noted above, the CD44-/- mouse has no apparent phenotype and the lymphatic endothelia are quite normal in these mice. Another candidate compensatory receptor in the absence of CD44 is lymphatic vascular endothelial hyaluronan receptor 1 (LYVE-1), a small HA-binding receptor expressed at high levels in the lymphatics. LYVE- 1 is a type I, single-pass $\sim 60 \mathrm{kDa}$ plasma membrane glycoprotein containing 322 amino acids. A Link domain, which comprises the bulk of the receptor ectodomain, binds only HA, not CS or HS [129]. The cysteines (Cys) of this Link domain are highly conserved, but only three other residues $\left(\mathrm{Lys}^{46}, \mathrm{Try}^{87}\right.$, and $\mathrm{Asn}^{109}$ ) are conserved in the Link family and known to be involved with HA binding. Much of the LYVE-1 Link domain is nonconserved, which may explain why this particular Link domain only binds HA and none of the other GAGs. On the C-terminal side of the Link domain, there are several tracts of basic amino acids, e.g., RRKK ${ }^{198}$, which may also assist in HA binding. Like CD44, LYVE-1 contains one free Cys in the transmembrane region that may function as a dimerization stabilizer during receptor- mediated endocytosis [130]. Two common pathways for endocytosis are entered by targeting either to clathrin-coated pits utilizing tyrosine-based motifs, e.g., YXXB or NPXY, where $\mathrm{X}$ is any amino acid and $\mathrm{B}$ is an amino acid with a bulky hydrophobic side-group [131], or to caveolae utilizing a hydrophobic motif, e.g., YXXXFXF [132]. LYVE-1 does not contain consensus sequences for coated-pit-mediated endocytosis, and caveolin-mediated endocytosis by LYVE-1 has not been reported. It is quite possible that LYVE-1-mediated uptake is similar to CD44-mediated endocytosis in that the route of endocytosis is unique with a recycling receptor going to a specialized compartment where HA is dissociated from the receptor and then delivered to an acidic lysosome-like organelle [66]. However, this unusual endocytic mechanism is only proven in keratinocytes and is not known to exist in other cell types. 
LYVE-1 expression is limited to lymph vessel endothelium, but not blood vascular endothelium, with the possible exception of the liver sinusoids [133]. Tissues expressing LYVE-1 include lymph vessel endothelia draining GI, skin, breast, lymph node, and salivary gland tissues [129]. Since LYVE-1 is restricted to lymphatic endothelia, it has been utilized as a distinct marker for lymphangiogenesis. Currently, the mechanisms stimulating and directing lymphangiogenesis are largely unknown. Lymphangiogenesis is a similar process to hemangiogenesis, which is the outgrowth of new blood vessels into tissues. Current evidence indicates that lymphangiogenesis is mediated by vascular endothelial growth factor (VEGF-C) and -D binding to VEGFR3 to expand lymphatic vessel outgrowth. Likewise, hemangiogenesis is mediated by VEGF-A binding with VEGFR1 and VEGFR2 to promote blood vessel growth [134]. Lymphangiogenesis occurs naturally in growing tissues and grafted tissues. Like hemangiogenesis, lymphangiogenesis facilitates the trafficking of monocytes and leukocytes throughout the tissue. Increased lymphangiogenesis is highly correlated with the rejection of graft tissue [135] and poor outcome due to premalignant breast cancer metastasis [136]. In contrast, decreased lymphangiogenesis and increased hemangiogenesis are implicated in the development of malignant cancer in which the trafficking of white blood cells is restricted [137]. A high probability of metastasis and poor outcome is observed if the cancer tissue retains the lymph vessel endothelium, allowing the trafficking of cancerous cells to spread to other areas of the body [138-140].

It is not clear how LYVE-1 fits into the lymphangiogenesis story besides being a good marker for lymph endothelium. The primary route of metastatic malignant cells and part of the circulatory route of white blood cells is through the lymphatic system. Like CD44, which is a homing receptor for leukocytes, LYVE-1 may facilitate the binding, rolling, and extravasation of leukocytes by its recognition of HA. Modeling the Link domain of LYVE-1 onto the CD44 Link crystal structure reveals that the LYVE-1 Link domain may have an on/off switching mechanism that works similarly to the Nglycan modification mechanism on CD44 that regulates HA binding [82]. Indirect evidence of this switch is evident since the receptor is functionally "off" when expressed in B-lymphoma and cervical carcinoma cells, but functionally "on" when expressed in 293 or COS cells. Treatment of 293T cells expressing LYVE-1 with phorbol 12-myristate 13-acetate increases HA binding to LYVE-1 [141]. LYVE-1 may also transport HA across the lymphatic endothelium from the interstitium to the lymph in a transcytosis process. This idea is supported by the findings that LYVE-1 is on both the luminal and abluminal sides of lymphatic capillaries and that the lymphatic endothelia contains intracytoplasmic vesicle clusters that may form stable channels that facilitate this type of transport [130, 142]. The specific functional aspects of how LYVE-1, a distinct and interesting marker for the lymph endothelium, uses HA in cellular transport has yet to be discovered.

\section{Hyaluronic Acid Receptor for Endocytosis}

The hyaluronic acid receptor for endocytosis (HARE) is the primary scavenger receptor for systemic HA and CS turnover. The adult human body typically contains about $15 \mathrm{~g}$ of HA of which approximately one-third or $5 \mathrm{~g}$ is catabolized daily [143-145]. About $50 \%$ of the total HA is located in the epidermal layers with the remaining enriched in the bursa of the joints, the vitreous humor of the eye and, to varying extents, all other tissues. The catabolism of HA occurs at two levels: local, within the immediate areas of a tissue, and systemic, involving transport of HA to distal sites. As previously discussed, CD44, which is found on many cell types of the body, handles much of the local HA turnover. However, in the 1980s, Laurent and coworkers observed that most HA is not broken down at the local tissue level, but is rather transported through the lymphatic and vascular systems to distal sites to be catabolized in the sinusoidal endothelium of the lymph nodes and liver [145-147]. The general route of HA turnover involves local partial cleavage in tissues, possibly by hyaluronidases or mechanical/oxidative degradation in the interstitium. The large HA fragments (probably with bound proteoglycans) first perfuse through the lymphatic system, which catabolizes about $85 \%$ of it, with the remaining amount entering the peripheral circulation via the thoracic duct. This resid- 
ual HA is then internalized and degraded in the liver sinusoids; maintaining steady-state HA blood levels at $<50 \mathrm{ng} / \mathrm{mL}$.

HARE was first identified, purified, and characterized from rat liver sinusoidal endothelial cells $[148,149]$. Using cross-reacting monoclonal antibodies, the HARE protein from human spleen was then characterized [150], and soon after, molecular cloning of the rat and human HARE were reported [151, 152]. HARE is expressed as two isoforms; a large $300 \mathrm{kDa}$ (rat) or $315 \mathrm{kDa}$ (human) and a smaller proteolytically processed $175 \mathrm{kDa}$ (rat) or $190 \mathrm{kDa}$ (human) form. The smaller rat and human recombinant HARE isoforms were characterized in stable cell lines by Zhou et al. [151] and Harris et al. [152]. The full-length human isoform was cloned and expressed in 293 cell lines and named Stabilin-2 due to its close homology to Stabilin-1, which had no known function at that time [153, 154]. Subsequently, HARE was also named FEEL-2 [155, 156], by other groups, although in the field of glycobiology, it is commonly referred to as HARE as it will be in this chapter. Although earlier reports questioned the legitimacy of the smaller isoform [157], we confirmed that cells expressing the human full-length recombinant protein from cDNA always produce both HARE isoforms [154].

Human HARE is expressed primarily in the medullary sinuses of lymph nodes, sinusoids of the liver, and venous sinuses of the spleen. It has also been reported in mice in specialized tissues such as corneal and lens epithelium, mesenchymal cells of heart valves, ependymal cells lining the ventricles of the brain, and in prismatic epithelial cells covering the renal papillae [158, 159]. The human gene, located on chromosome 12q23.3, is $180.2 \mathrm{~kb}$, contains 69 exons and encodes a 2551 amino acid type I receptor (Figure 2). The glycoprotein mass by SDS-PAGE, including all glycosylation modifications, is $315 / 300 \mathrm{kDa}$ and $190 / 175 \mathrm{kDa}$ for both rat/human isoforms. The smaller isoform is identical to the C-terminal 1416 (human)/1431 (rat) amino acids of the full-length HARE protein. A subset of cellular HARE is proteolytically cleaved near or at the plasma membrane, but the protease involved remains unidentified, and the proteolytic site does not contain a consensus sequence for any known proteases [154]. Both isoforms contain numerous fascilin-like and EGF-like domains in complex Cys-rich areas and one Link domain near the plasma membrane domain. The function of either the fascilin- and EGFlike domains is unknown, although they may interact with extracellular/matrix components during adhesion, signaling, or ligand interactions. We recently showed that the HARE Link domain is the primary HA-binding domain [172, 173]. Since the HARE and TSG-6 Link domains share the greatest degree of homology [7] and bind HA with high affinity, it is reasonable that the Link domain is the primary HA-binding domain of HARE, responsible for $\sim 90 \%$ of the binding activity.

HA-HARE complex formation is high-affinity $[154,160]$ and cation-independent [161] and internalization of complexes proceeds via the clathrin-coated pit pathway [151,162, 163]. The cytoplasmic domain contains three motifs involved in clathrin/ AP-2 targeting or intracellular trafficking after endocytosis (e.g., YSYFRI, FQHF, and NPLY) [174]. Subcellular localization of recombinant rat HARE is primarily at the cell surface and in endocytic vesicles, but not lysosomes, suggesting that HARE is recycled back to the cell surface [151]. Additionally, cycloheximide treatment of isolated rat liver endothelial cells (LEC) revealed that endocytosis of ${ }^{125} \mathrm{I}-\mathrm{HA}$ proceeds uninterrupted for several hours, and the receptors recycle from endosomes back to the cell surface every $\sim 28$ min to mediate uptake of additional HA [162]. Both rat and human HARE recycle in a similar fashion; recombinant $190 \mathrm{kDa}$ human HARE in stable 293 Flp-In cell lines recycles every $\sim 8.5 \mathrm{~min}$, whereas the recombinant $175 \mathrm{kDa}$ rat HARE in stable SK-Hep1 cell lines recycles every $20 \mathrm{~min}[151,152]$. The differences in receptor recycling times is more likely due to cellular machinery differences rather than intrinsic to the receptor itself.

\subsection{HARE and GAG Binding}

A primary role for HARE is to bind and endocytose HA, but it also internalizes CS-A, CS-C, CSD, CS-E, DS, and Chon [152, 172]. It has also been reported to bind advanced glycation end-products, collagen N-terminal propeptides, and Gram-negative and Gram-positive bacteria [155, 156, 163]. HA 
used in our standard endocytic experiments is radiolabeled with ${ }^{125}$ I only at the reducing end, which keeps virtually all of the HA polymer native and unmodified. To assess binding of free CS, HP, or HS chains, LECs were incubated with both the ${ }^{125} \mathrm{I}-\mathrm{HA}$ and an unlabeled GAG in competition assays. Interference of ${ }^{125} \mathrm{I}$-HA binding by CS and HP in rat LEC was discovered in the 1980s [162, 164, 165]. Oynebraten et al. [166] found that rat LECs efficiently endocytosed and degraded labeled Serglycin, the serum proteoglycans rich in CS and HS chains. Serglycin also interfered with HA binding; further supporting the conclusion that HARE is "promiscuous" and able to recognize many different GAGs [158, 167, 172]. As noted previously, CD44 also binds and internalizes Serglycin, but the efficiency of binding and endocytosis by HARE is much greater. Later, when the $190 \mathrm{kDa}$ HARE was cloned from human spleen and expressed in 293 Flp-In cells, all of the binding and endocytic assays indicated that Chon and all of the CS types competed for the binding of labeled HA to varying degrees. Inhibition of HA endocytosis was most pronounced with CS-A, CS-C, and CS-D, but was not observed with HP, HS, or KS [152]. The discrepancy in results regarding HP competition in earlier [162] versus recent [152] reports leads us to believe the HP used in earlier experiments may have contained other GAG impurities. The broad GAG-binding specificity of HARE, its location in lymphatic and liver sinusoids, and its fast recycling activity as a coated-pit mediated endocytic receptor strongly argues that HARE is the primary scavenger receptor responsible for the clearance of multiple GAGs, including HA, rather than LYVE-1, CD44, RHAMM, or any other known HA/GAG receptor. For example, although LYVE-1 is located in lymphoid endothelium, it is not likely a systemic scavenger receptor for HA or CS because its binding affinity for HA is too low to be efficient and its endocytic uptake rate is less than half that for HARE. We also discovered that HARE is a clearance receptor for $\mathrm{HP}$, and that the $\mathrm{HA}$ and $\mathrm{HP}$ binding sites are separate and independent $[172,173]$.

\subsection{HARE and Development}

HA is a molecule that facilitates cell motility in cancer and development, for example, as seen in the HA/CD44/RHAMM studies. Since HARE is a recently discovered HA receptor, studies involving its role in development are few. HA and other proteoglycans are the foundation of endocardial development, chamber septation, and valve development. These ECM components participate in cell signaling cascades and creating space for cell infiltration that is necessary for cellular differentiation as the organ develops [168-170]. A study examining the role of fascilin-containing genes expressed in heart development shows that Stabilin-1, HARE, $\beta$-IgH3, and periostin are regulated both spatially and temporally as the heart develops $[159,171]$. HARE expression is restricted to the postnatal mature valve endothelial cells, an area rich in GAGs. Another preliminary study indicates that HARE expression oscillates as the fetal rat liver develops. Using histological methods, HARE expression is present as early as day 13 , maximizes by day 15 , disappears by day 17 , and then reappears on day 18 (P. H. Weigel, unpublished data). It is not known what regulates this differential gene expression although the production and scavenging of HA by hyaladherins in organogenesis is critical for proper development.

\section{Conclusion and Future Directions}

The basic ligand-binding functionalities of the HA/CS receptors are fairly well known. Tissue/ ECM remodeling, organ development, and responses to diseases caused by either intrinsic pathologies (cancer, arthritis, etc.) or external invaders caused by bacterial or viral infections are more of the complex roles that involve the HA/CS receptors. There are considerable redundancies in place to handle the maintenance of basic life functions in case one of these receptors fails. This is most evident in the CD44 and LYVE-1 knockout mice, which contain no obvious phenotype, although multiple functions (especially for CD44) have been attributed to the respective receptor. However, each receptor is necessary for the optimal response in the organism to meet all of the different challenges associated with life. One of the future challenges for the HA/CS receptors is the understanding of how 
the molecular machinery is tied in with physiological responses. Despite the numerous studies on the subject of endocytosis, the molecular pathways for receptor internalization, ligand uncoupling, gene regulation, and transport are only vaguely understood for these receptors. In addition, it is not known how these pathways and molecular mechanisms are altered in cases of cancer or infection. Current research is still on the observation stage in which we are dissecting the mechanical parts and we have much to learn on how these parts work together.

\section{Acknowledgments}

We thank Janet A. Weigel for help assembling the manuscript and references. Some of the research described here was supported by National Institute of General Medical Sciences grants GM69961, GM35978, and F32 GM070262 from the National Institutes of Health.

\section{References}

1. R. Stern, A. A. Asari, and K. N. Sugahara, Hyaluronan fragments: An information-rich system, Eur. J. Cell Biol. 85, 699-715, 2006.

2. F. P. Barry, L. C. Rosenberg, J. U. Gaw, T. J. Koob, and P. J. Neame, N- and O-linked keratan sulfate on the hyaluronan binding region of aggrecan from mature and immature bovine cartilage, J. Biol. Chem. 270, 20516-20524, 1995.

3. W. W. Kao and C. Y. Liu, Roles of lumican and keratocan on corneal transparency, Glycoconj. J. 19, 275-285, 2002.

4. J. Dudhia, Aggrecan, aging and assembly in articular cartilage. Cell Mol. Life Sci. 62, 2241-2256, 2005.

5. D. Kohda, C. J. Morton, A. A. Parkar, H. Hatanaka, F. M. Inagaki, I. D. Campbell, and A. J. Day, Solution structure of the link module: A hyaluronan-binding domain involved in extracellular matrix stability and cell migration. Cell 86, 767-775, 1996.

6. A. A. Parkar and A. J. Day, Overlapping sites on the Link module of human TSG-6 mediate binding to hyaluronan and chrondroitin-4-sulphate, FEBS Lett. 410, 413-417, 1997.

7. C. D. Blundell, A. Almond, D. J. Mahoney, PL. DeAngelis, I. D. Campbell, and A. J. Day, Towards a structure for a TSG-6-hyaluronan complex by modeling and NMR spectroscopy: Insights into other members of the link module superfamily, J. Biol. Chem. 280, 18189-18201, 2005.

8. C. M. Milner, V. A. Higman, and A. J. Day, TSG-6: A pluripotent inflammatory mediator? Biochem. Soc. Trans. 34, 446-450, 2006.

9. A. A. Parkar, J. D. Kahmann, S. L. T. Howat, M. T. Bayliss, and A. J. Day, TSG-6 interacts with hyaluronan and aggrecan in a $\mathrm{pH}$-dependent manner via a common functional element: Implications for its regulation in inflamed cartilage, FEBS Lett. 428, 171-176, 1998.

10. H. G. Wisniewski, J. C. Hua, D. M. Poppers, D. Naime, J. Vilcek, and B. N. Cronstein, TNF/IL-1-inducible protein TSG-6 potentiates plasmin inhibition by inter-alpha-inhibitor and exerts a strong anti-inflammatory effect in vivo, J. Immunol. 156, 1609-1615, 1996.

11. R. Forteza, S. M. Casalino-Matsuda, M. E. Monzon, E. Fries, M. S. Rugg, C. M. Milner, and A. J. Day, TSG-6 potentiates the anti-tissue kallikrein activity of inter- $\alpha$-inhibitor through bikunin release, Am. J. Respir. Cell Mol. Biol. 36, 20-31, 2006.

12. A. Salustri, C. Garlanda, E. Hirsch, M. De Acetis, A. Maccagno, B. Bottazzi, A. Doni, A. Bastone, G. Mantovani, P. B. Peccoz, G. Salvatori, D. J. Mahoney, A. J. Day, G. Siracusa, L. Romani, and A. Mantovani, PTX3 plays a key role in the organization of the cumulus oophorus extracellular matrix and in in vivo fertilization. Development 131, 1577-1586, 2004.

13. S. A. Kuznetsova, A. J. Day, D. J. Mahoney, M. S. Rugg, D. F. Mosher, and D. D. Roberts, The N-terminal module of thrombospondin-1 interacts with the link domain of TSG-6 and enhances its covalent association with the heavy chains of inter- $\alpha$-trypsin inhibitor, J. Biol. Chem. 280, 30899-30908, 2005.

14. J. Y. Park, Y. Q. Su, M. Ariga, E. Law, S. L. C. Jin, and M. Conti, EGF-like growth factors as mediators of LH action in the ovulatory follicle. Science 303, 682-684, 2004.

15. C. Fulop, A. Salustri, and V. C. Hascall, Coding sequence of a hyaluronan synthase homologue expressed during expansion of the mouse cumulus-oocyte complex. Arch. Biochem. Biophys. 337, 261-266, 1997. 
16. O. Carrette, R. V. Nemade, A. J. Day, A. Brickner, and W. J. Larsen, TSG-6 is concentrated in the extra-cellular matrix of mouse cumulus oocyte complexes through hyaluronan and inter-alpha-inhibitor binding, Biol. Reprod. 65, 301-308, 2001.

17. D. Mukhopadhyay, V. C. Hascall, A. J. Day, A. Salustri, and C. Fulop, Two distinct populations of tumor necrosis factor-stimulated gene-6 protein in the extracellular matrix of expanded mouse cumulus cell-oocyte complexes. Arch. Biochem. Biophys. 394, 173-181, 2001.

18. T. Fujimoto, R. C. Savani, M. Watari, A. J. Day, and J. F. Strauss III, Induction of the hyaluronic acid-binding protein, tumor necrosis factor-stimulated gene-6, in cervical smooth muscle cells by tumor necrosis factor- $\alpha$ and prostaglandin E2, Am. J. Pathol. 160, 1495-1502, 2002.

19. A. Salustri, M. Yanagishita, and V. C. Hascall, Synthesis and accumulation of hyaluronic acid and proteoglycans in the mouse cumulus cell-oocyte complex during follicle-stimulating hormone-induced mucification, J. Biol. Chem. $264,13840-13847,1989$.

20. C. Fulop, S. Szanto, D. Mukhopadhyay, T. Bardos, R. V. Kamath, M. S. Rugg, A. J. Day, A. Salustri, V. C. Hascall, T. T. Giant, and K. Mikecz, Impaired cumulus mucification and female sterility in tumor necrosis factor-induced protein-6 deficient mice, Development 130, 2253, 2003.

21. H. G. Wisniewski, W. H. Burgess, J. D. Oppenheim, and J. Vilcek, TSG-6, an arthritis-associated hyaluronan binding protein, forms a stable complex with the serum protein inter-alpha-inhibitor, Biochemistry 33, 7423-7429, 1994.

22. C. M. Lilly, H. Tateno, T. Oguma, E. Israel, and L. A. Sonna, Effects of allergen challenge on airway epithelial cell gene expression. Am. J. Respir. Crit. Care Med. 171, 579-586, 2005.

23. J. J. Enghild, G. Salvesen, I. B. Thogersen, Z. Valnickova, S. V. Pizzo, and S. A. Hefta, Presence of the protein-glycosaminoglycan - protein covalent cross-link in the inter-alpha-inhibitor-related proteinase inhibitor heavy chain 2/bikunin, J. Biol. Chem. 268, 8711-8716, 1993.

24. K. W. Sanggaard, H. Karring, Z. Valnickova, I. B. Thogersen, and J. J. Enghild, The TSG-6 and I $\alpha$ I interaction promotes a transesterification cleaving the protein-glycosaminoglycan-protein (PGP) cross-link, J. Biol. Chem. 280, 11936-11942, 2005.

25. M. Zhao, M. Yoneda, Y. Ohashi, S. Kurono, H. Iwata, Y. Ohnuki, and K. Kimata, Evidence for the covalent binding of SHAP, heavy chains of inter-alpha-trypsin inhibitor, to hyaluronan, J. Biol. Chem. 270, 26657-26663, 1995.

26. M. S. Rugg, A. C. Willis, D. Mukhopadhyay, V. C. Hascall, E. Fries, C. Fulop, C. M. Milner, and A. J. Day, Characterization of complexes formed between TSG-6 and inter-alpha-inhibitor that act as intermediates in the covalent transfer of heavy chains on to hyaluronan, J. Biol. Chem. 280, 25674-25686, 2005.

27. L. Huang, M. Yoneda, and K. Kimata, A serum-derived hyaluronan-associated protein (SHAP) is the heavy chain of the inter alpha-trypsin inhibitor, J. Biol. Chem. 268, 26725-26730, 1993.

28. L. Zhuo and K. Kimata, Cumulus oophorus extracellular matrix: Its construction and regulation. Cell Struct. Funct. 26, 189-196, 2001.

29. L. Chen, S. J. T. Mao, and W. J. Larsen, Identification of a factor in fetal bovine serum that stabilizes the cumulus extracellular matrix: A role for a member of the inter- $\alpha$-trypsin inhibitor family, J. Biol. Chem. 267, 12380-12386, 1992.

30. D. J. Mahoney, C. D. Blundell, and A. J. Day, Mapping the hyaluronan-binding site on the link module from human tumor necrosis factor-stimulated gene-6 by site-directed mutagenesis, J. Biol. Chem. 276, 22764-22771, 2001.

31. N. Busso and J. A. Hamilton, Extravascular coagulation and the plasminogen activator/plasmin system in rheumatoid arthritis, Arthritis Rheum. 46, 2268-2279, 2002.

32. F. O. Akenami, V. Siren, M. Wessman, M. Koskiniemi, and A. Vaheri, Tissue plasminogen activator gene expression in multiple sclerosis brain tissue, J. Neurol. Sci. 165, 71-76, 1999.

33. M. W. Cunningham, Pathogenesis of group A streptococcal infections, Clin. Microbiol. Rev. 13, 470-511, 2000.

34. J. M. Rakic, C. Maillard, M. Jost, K. Bajou, V. Masson, L. Devy, V. Lambert, J. M. Foidart, and A. Noel, Role of plasminogen activator-plasmin system in tumor angiogenesis, Cell Mol. Life Sci. 60, 463-473, 2003.

35. W. J. Murdoch and M. L. Gottsch, Proteolytic mechanisms in the ovulatory folliculo-luteal transformation, Connect Tissue Res. 44, 50-57, 2003.

36. D. J. Mahoney, B. Mulloy, M. J. Forster, C. D. Blundell, E. Fries, C. M. Milner, and A. J. Day, Characterization of the interaction between tumor necrosis factor-stimulated Gene-6 and heparin: Implications for the inhibition of plasmin in extracellular matrix microenvironments, J. Biol. Chem. 280, 27044-27055, 2005.

37. A. I. Yudin, M. W. Li, K. R. Robertson, G. N. Cherr, and J. W. Overstreet, Characterization of the active site of monkey sperm hyaluronidase, J. Reprod. Fertil. 121, 735-743, 2001.

38. V. Doyen, M. Rubio, D. Braun, T. Nakajima, J. Abe, H. Saito, G. Delespesse, and M. Sarfati, Thrombospondin 1 is an autocrine negative regulator of human dendritic cell activation, J. Exp. Med. 198, 1277-1283, 2003. 
39. S. J. Suchard, L. A. Boxer, and V. M. Dixit, Activation of human neutrophils increases thrombospondin receptor expression, J. Immunol. 147, 651-659, 1991.

40. A. Agah, T. R. Kyriakides, J. Lawler, and P. Bornstein, The lack of thrombospondin-1 (TSP1) dictates the course of wound healing in double-TSPl/TSP2-null mice. Am. J. Pathol. 161, 831-839, 2002.

41. J. Entwistle, S. W. Zhang, B. H. Yang, C. Wong, Q. Li, C. L. Hall, A. Jingbo, M. Mowat, A. H. Greenberg, and E. A. Turley, Characterization of the murine gene encoding the hyaluronan receptor RHAMM, Gene 163, 233-238, 1995.

42. E. A. Turley, D. Moore, and L. J. Hayden, Characterization of hyaluronate binding proteins isolated from 3 T3 and murine sarcoma virus transformed 3T3 cells. Biochemistry 26, 2997-3005, 1987.

43. E. A. Turley, Purification of a hyaluronate-binding protein fraction that modifies cell social behavior, Biochem. Biophys. Res. Commun. 108, 1016-1024, 1982.

44. E. A. Turley, A. J. Belch, S. Poppema, and L. M. Pilarski, Expression and function of a receptor for hyaluronan-mediated motility on normal and malignant lymphocytes-B, Blood 81, 446-453, 1993.

45. C. L. Hall, L. A. Lange, D. A. Prober, S. Zhang, and E. A. Turley, pp60(c-src) is required for cell locomotion regulated by the hyaluronan receptor RHAMM, Oncogene 13, 2213-2224, 1996.

46. E. A. Turley, L. Austen, K. Vandeligt, and C. Clary, Hyaluronan and a cell-associated hyaluronan binding protein regulate the locomotion of ras-transformed cells, J. Cell Biol. 112, 1041-1047, 1991.

47. M. Crainie, A. R. Belch, M. J. Mant, and L. M. Pilarski, Overexpression of the receptor for hyaluronan-mediated motility (RHAMM) characterizes the malignant clone in multiple myeloma: Identification of three distinct RHAMM variants. Blood 93, 1684-1696, 1999.

48. B. H. Yang, L. Y. Zang, and E. A. Turley, Identification of 2 hyaluronan-binding domains in the hyaluronan receptor RHAMM, J. Biol. Chem. 268, 8617-8623, 1993.

49. B. H. Yang, B. L. Yang, R. C. Savani, and E. A. Turley, Identification of a common hyaluronan binding motif in the hyaluronan binding proteins rhamm, cd44 and link protein, EMBO J. 13, 286-296, 1994.

50. M. R. Ziebell, Z. G. Zhao, B. Luo, Y. Luo, E. A. Turley, and G. D. Prestwich, Peptides that mimic glycosaminoglycans: High-affinity ligands for a hyaluronan binding domain, Chem. Biol. 8, 1081-1094, 2001.

51. V. Assmann, J. F. Marshall, C. Fieber, M. Hofmann, and I. R. Hart, The human hyaluronan receptor RHAMM is expressed as an intracellular protein in breast cancer cells, J. Cell Sci. 111, 1685-1694, 1998.

52. C. Samuelsson and S. Gustafson, Studies on the interaction between hyaluronan and a rat colon cancer cell line, Glycoconj. J. 15, 169-175, 1998.

53. R. C. Savani, C. Wang, B. H. Yang, S. W. Zhang, M. G. Kinsella, T. N. Wight, R. Stern, D. M. Nance, and E. A. Turley, Migration of bovine aortic smooth muscle cells after wounding injury - the role of hyaluronan and RHAMM, J. Clin. Invest. 95, 1158-1168, 1995.

54. S. P. Evanko, W. T. Parks, and T. N. Wight, Intracellular hyaluronan in arterial smooth muscle cells: Association with microtubules, RHAMM, and the mitotic spindle, J. Histochem. Cytochem. 52, 1525-1536, 2004.

55. V. B. Lokeshwar and M. G. Selzer, Differences in hyaluronic acid-mediated functions and signaling in arterial, microvessel, and vein-derived human endothelial cells, J. Biol. Chem. 275, 27641-27649, 2000.

56. I. Hus, J. Rolinski, J. Tabarkiewicz, K. Wojas, A. Bojarska-Junak, J. Greiner, K. Giannopoulos, A. Dmoszynska, and M. Schmitt, Allogeneic dendritic cells pulsed with tumor lysates or apoptotic bodies as immunotherapy for patients with early-stage B-cell chronic lymphocytic leukemia, Leukemia 19, 1621-1627, 2005.

57. J. Greiner, M. Ringhoffer, M. Taniguchi, A. Schmitt, D. Kirchner, G. Krahn, V. Heilmann, J. Gschwend, L. Bergmann, H. Dohner, and M. Schmitt, Receptor for hyaluronan acid-mediated motility (RHAMM) is a new immunogenic leukemia-associated antigen in acute and chronic myeloid leukemia, Exp. Hematol. 30, 1029-1035, 2002.

58. T. Ahrens, V. Assmann, C. Fieber, C. C. Termeer, P. Herrlich, M. Hofmann, and J. C. Simon, CD44 is the principal mediator of hyaluronic-acid-induced melanoma cell proliferation, J. Invest. Dermatol. 116, 93-101, 2001.

59. C. Wang, A. D. Thor, D. H. Moore, Y. Zhao, R. Kerschmann, R. Stern, PH. Watson, and E. A. Turley, The overexpression of RHAMM, a hyaluronan-binding protein that regulates ras signaling, correlates with overexpression of mitogenactivated protein kinase and is a significant parameter in breast cancer progression, Clin. Cancer Res. 4, 567-576, 1998.

60. V. Abetamann, H. F. Kern, and H. P. Elsasser, Differential expression of the hyaluronan receptors CD44 and RHAMM in human pancreatic cancer cells, Clin. Cancer Res. 2, 1607-1618, 1996.

61. Y. Akiyama, S. Jung, B. Salhia, S. Lee, S. Hubbard, M. Taylor, T. Mainprize, K. Akaishi, W. van Furth, and J. T. Rutka, Hyaluronate receptors mediating glioma cell migration and proliferation, J. Neurooncol. 53, 115-127, 2001.

62. A. Lugli, I. Ziobec, U. Gunthert, P. Minoo, K. Baker, L. Tornillo, L. Terracciano, and J. R. Jass, Overexpression of the receptor for hyaluronic acid mediated motility is an independent adverse prognostic factor in colorectal cancer, Mod. Pathol. 19, 1302-1309, 2006. 
63. C. L. Hall, C. Wang, L. A. Lange, and E. A. Turley, Hyaluronan and the hyaluronan receptor RHAMM promote focal adhesion turnover and transient tyrosine kinase activity, J. Cell Biol. 126, 575-588, 1994.

64. P. H. Weigel, V. C. Hascall, and M. Tammi, Hyaluronan synthases, J. Biol. Chem. 272, 13997-14000, 1997.

65. S. P. Evanko and T. N. Wight, Intracellular localization of hyaluronan in proliferating cells, J. Histochem. Cytochem. 47, 1331-1341, 1999.

66. R. Tammi, K. Rilla, J. P. Pienimaki, D. K. Maccallum, M. Hogg, M. Luukkonen, V. C. Hascall, and M. Tammi, Hyaluronan enters keratinocytes by a novel endocytic route catabolism, J. Biol. Chem. 276, 35111-35122, 2001.

67. R. Stern, Devising a pathway for hyaluronan catabolism: Are we there yet?, Glycobiology 13, 105R-115R, 2003.

68. V. Assmann, D. Jenkinson, J. F. Marshall, and I. R. Hart, The intracellular hyaluronan receptor RHAMM/IHABP interacts with microtubules and actin filaments, J. Cell Sci. 112, 3943-3954, 1999.

69. C. A. Maxwell, J. J. Keats, M. Crainie, X. Sun, T. Yen, E. Shibuya, M. Hendzel, G. Chan, and L. M. Pilarski, RHAMM is a centrosomal protein that interacts with dynein and maintains spindle pole stability, Mol. Biol. Cell 14, 22622276, 2003.

70. S. Adamia, C. A. Maxwell, and L. M. Pilarski, Hyaluronan and hyaluronan synthases: Potential therapeutic targets in cancer, Curr. Drug Targets Cardiovasc. Haematol. Disord. 5, 3-14, 2005.

71. H. Li, L. Guo, J. W. Li, N. Liu, R. Qi, and J. Lui, Expression of hyaluronan receptors CD44 and RHAMM in stomach cancers: Relevance with tumor progression. Int. J. Oncol. 17, 927-932, 2000.

72. D. T. Rein, K. Roehrig, T. Schondorf, A. Lazar, M. Fleisch, D. Niederacher, H. G. Bender, and P. Dall, Expression of the hyaluronan receptor RHAMM in endometrial carcinomas suggests a role in tumour progression and metastasis, J. Cancer Res. Clin. Oncol. 129, 161-164, 2003.

73. S. L. Gares and L. M. Pilarski, Balancing thymocyte adhesion and motility: A functional linkage between betal integrins and the motility receptor RHAMM, Dev. Immunol. 7, 209-225, 2000.

74. V. Nehls and W. Hayen, Are hyaluronan receptors involved in three-dimensional cell migration?, Histol. Histopathol. 15, 629-636, 2000.

75. A. Masellissmith, A. R. Belch, M. J. Mant, E. A. Turley, and L. M. Pilarski, Hyaluronan-dependent motility of B cells and leukemic plasma cells in blood, but not of bone marrow plasma cells, in multiple myeloma: Alternate use of receptor for hyaluronan-mediated motility (RHAMM) and CD44, Blood 87, 1891-1899, 1996.

76. E. A. Turley, M. Z. Hossain, T. Sorokan, L. M. Jordan, and J. I. Nagy, Astrocyte and microglial motility in vitro is functionally dependent on the hyaluronan receptor RHAMM, Glia 12, 68-80, 1994.

77. P. H. Weigel, G. M. Fuller, and R. D. LeBoeuf, A model for the role of hyaluronic acid and fibrin in the early events during the inflammatory response and wound healing, J. Theor. Biol. 119, 219-234, 1986.

78. C. L. Hall and E. A. Turley, Hyaluronan: RHAMM mediated cell locomotion and signaling in tumorigenesis, J. Neurooncol. 26, 221-229, 1995.

79. E. A. Turley, P. W. Noble, and L. Y. W. Bourguignon, Signaling properties of hyaluronan receptors, J. Biol. Chem. 277, 4589-4592, 2002.

80. A. P. Spicer, M. L. Roller, S. A. Camper, J. D. McPherson, J. J. Wasmuth, S. Hakim, C. Wang, E. A. Turley, and J. A. McDonald, The human and mouse receptors for hyaluronan-mediated motility, RHAMM, genes (HMMR) map to human chromosome 5q33.2-qter and mouse chromosome 11, Genomics 30, 115-117, 1995.

81. H. Ponta, D. Wainwright, and P. Herrlich, The CD44 protein family. Int. J. Biochem. Cell Biol. 30, 299-305, 1998.

82. P. Teriete, S. Banerji, M. Noble, C. D. Blundell, A. J. Wright, A. R. Pickford, E. Lowe, D. J. Mahoney, M. I. Tammi, J. D. Kahmann, I. D. Campbell, A. J. Day, and D. G. Jackson, Structure of the regulatory hyaluronan binding domain in the inflammatory leukocyte homing receptor CD44, Mol. Cell 13, 483-496, 2004.

83. M. C. Levesque and B. F. Haynes, TNFoc and IL-4 regulation of hyaluronan binding to monocyte CD44 involves posttranslational modification of CD44, Cell. Immunol. 193, 209-218, 1999.

84. K. Gee, M. Kozlowski, and A. Kumar, Tumor necrosis factor- $\alpha$ induces functionally active hyaluronan-adhesive CD44 by activating sialidase through p38 mitogen-activated protein kinase in lipopolysaccharide-stimulated human monocytic cells, J. Biol. Chem. 278, 37275-37287, 2003.

85. H. Kawashima, M. Hirose, J. Hirose, D. Nagakubo, A. H. K. Plaas, and M. Miyasaka, Binding of a large chondroitin sulfate/dermatan sulfate proteoglycan, versican, to L-selectin, P-selectin, and CD44, J. Biol. Chem. 275, 3544835456, 2000.

86. T. Murai, N. Sougawa, H. Kawashima, K. Yamaguchi, and M. Miyasaka, CD44-chondroitin sulfate interactions mediate leukocyte rolling under physiological flow conditions, Immunol. Lett. 93, 163-170, 2004.

87. N. Toyama-Sorimachi, F. Kitamura, H. Habuchi, Y. Tobita, K. Kimata, and M. Miyasaka, Widespread expression 
of chondroitin sulfate-type serglycins with CD44 binding ability in hematopoietic cells, J. Biol. Chem. 272, 2671426719, 1997.

88. S. O. Kolset and J. T. Gallagher, Proteoglycans in haemopoietic cells, Biochim. Biophys. Acta 1032, 191-211, 1990.

89. M. Grujic, T. Braga, A. Lukinius, M. L. Eloranta, S. D. Knight, G. Pejier, and M. Abrink, Serglycin-deficient cytotoxic T lymphocytes display defective secretory granule maturation and granzyme B storage, J. Biol. Chem. 280, 33411-33418, 2005.

90. S. M. Raja, B. Wang, M. Dantuluri, U. R. Desai, B. Demeler, K. Spiegel, S. S. Metkar, and C. J. Froelich, Cytotoxic cell granule-mediated apoptosis. Characterization of the macromolecular complex of granzyme B with serglycin, J. Biol. Chem. 277, 49523-49530, 2002.

91. S. S. Metkar, B. Wang, S. Aguilar, S. M. Raja, L. Uhlin-Hansen, E. Podack, J. A. Trapani, and C. J. Froelich, Cytotoxic cell granule-mediated apoptosis: Perforin delivers granzyme B-serglycin complexes into target cells without plasma membrane pore formation. Immunity 16, 417-428, 2002.

92. N. Toyamasorimachi and M. Miyasaka, A novel ligand for CD44 is sulfated proteoglycan, Int. Immunol. 6, 655$660,1994$.

93. N. Toyamasorimachi, H. Sorimachi, Y. Tobita, F. Kitamura, H. Yagita, K. Suzuki, and M. Miyasaka, A novel ligand for CD44 is serglycin, a hematopoietic cell lineage-specific proteoglycan-Possible involvement in lymphoid cell adherence and activation, J. Biol. Chem. 270, 7437-7444, 1995.

94. M. Culty, H. A. Nguyen, and C. B. Underhill, The hyaluronan receptor (CD44) participates in the uptake and degradation of hyaluronan, J. Cell Biol. 116, 1055-1062, 1992.

95. Q. Hua, C. B. Knudson, and W Knudson, Internalization of hyaluronan by chondrocytes occurs via receptor-mediated endocytosis, J. Cell Sci. 106, 365-375, 1993.

96. A. C. Smith, J. T. Cirulis, J. E. Casanova, M. A. Scidmore, and J. H. Brumell, Interaction of the Salmonella-containing vacuole with the endocytic recycling system, J. Biol. Chem. 280, 24634-24641, 2005.

97. P. G. McGuire, J. J. Castellot, and R. W Orkin, Size-dependent hyaluronate degradation by cultured cells, J. Cell. Physiol. 133, 267-276, 1987.

98. C. B. Underhill, H. A. Nguyen, M. Shizari, and M. Culty, CD44 positive macrophages take up hyaluronan during lung development, Dev. Biol. 155, 324-336, 1993.

99. D. J. Aguiar, W. Knudson, and C. B. Knudson, Internalization of the hyaluronan receptor CD44 by chondrocytes, Exp. Cell Res. 252, 292-302, 1999.

100. M. Culty, M. Shizari, E. W. Thompson, and C. B. Underhill, Binding and degradation of hyaluronan by human breast cancer cell lines expressing different forms of CD44: Correlation with invasive potential, J. Cell Physiol. 160, 275-286, 1994.

101. R. Tammi and M. Tammi, Influence of retinoic acid on the ultrastructure and hyaluronic acid synthesis of adult human epidermis in whole skin organ culture, J. Cell. Physiol. 126, 389-398, 1986.

102. R. Tammi and M. Tammi, Correlations between hyaluronan and epidermal proliferation as studied by glucosamine and thymidine incorporations and staining of hyaluronan on mitotic keratinocytes, Exp. Cell Res. 195, 524-527, 1991.

103. V. B. Lokeshwar, N. Fregien, and L. Y. W. Bourguignon, Ankyrin-binding domain of CD44(GP85) is required for the expression of hyaluronic acid-mediated adhesion function, J. Cell Biol. 126, 1099-1109, 1994.

104. S. Tsukita, K. Oishi, N. Sato, J. Sagara, A. Kawai, and S. Tsukita, ERM family members as molecular linkers between the cell surface glycoprotein CD44 and actin-based cytoskeletons, 7. Cell Biol. 126, 391-401, 1994.

105. P. V. Jensen and L. I. Larsson, Actin microdomains on endothelial cells: Association with CD44, ERM proteins, and signaling molecules during quiescence and wound healing, Histochem. Cell Biol. 121, 361-369, 2004.

106. B. Formby and R. Stern, Phosphorylation stabilizes alternatively spliced CD44 mRNA transcripts in breast cancer cells: Inhibition by antisense complementary to casein kinase II mRNA, Mol. Cell Biochem. 187, 23-31, 1998.

107. A. I. McClatchey and M. Giovannini, Membrane organization and tumorigenesis - the NF2 tumor suppressor, Merlin, Genes Dev. 19, 2265-2277, 2005.

108. Y. Bai, Y. J. Liu, H. Wang, Y. Xu, I. Stamenkovic, and Q. Yu, Inhibition of the hyaluronan-CD44 interaction by merlin contributes to the tumor-suppressor activity of merlin, Oncogene 26, 836-850, 2006.

109. P. Teder, R. W. Vandivier, D. H. Jiang, J. R. Liang, L. Cohn, E. Pure, P. M. Henson, and P. W. Noble, Resolution of lung inflammation by CD44, Science 296, 155-158, 2002.

110. EL. Moffat, T. Han, Z. M. Li, M. D. Peck, R. E. Falk, P. B. Spalding, W. Jy, Y. S. Ahn, A. J. Chu, and L. Y. Bourguignon, Involvement of CD44 and the cytoskeletal linker protein ankyrin in human neutrophil bacterial phagocytosis, J. Cell Physiol. 168, 638-647, 1996. 
111. E. Vachon, R. Martin, J. Plumb, V. Kwok, R. W. Vandivier, M. Gloguaer, A. Kapus, X. Wang, C. W. Chow, S. Grinstein, and G. P. Downey, CD44 is a phagocytic receptor. Blood 107, 4149-4158, 2006.

112. H. Jiang, C. B. Knudson, and W. Knudson, Antisense inhibition of CD44 tailless splice variant in human articular chondrocytes promotes hyaluronan internalization. Arthritis Rheum. 44, 2599-2610, 2001.

113. H. Jiang, R. S. Peterson, W. H. Wang, E. Bartnik, C. B. Knudson, and W. Knudson, A requirement for the CD44 cytoplasmic domain for hyaluronan binding, pericellular matrix assembly, and receptor-mediated endocytosis in COS-7 cells, J. Biol. Chem. 277, 10531-10538, 2002.

114. B. Dome, B. Somlai, A. Ladanyi, K. Fazekas, M. Zoller, and J. Timar, Expression of CD44v3 splice variant is associated with the visceral metastatic phenotype of human melanoma, Virchows Arch. 439, 628-635, 2001.

115. S. Maula, R. L. Huuhtanen, C. P. Blomqvist, T. A. Wiklund, P. Laurila, and R. Ristamaki, The adhesion molecule CD44v6 is associated with a high risk for local recurrence in adult soft tissue sarcomas, Br. J. Cancer 84, 244-252, 2001.

116. R. Singh, S. Subramanian, J. M. Rhodes, and B. J. Campbell, Peanut lectin stimulates proliferation of colon cancer cells by interaction with glycosylated CD44v6 isoforms and consequential activation of c-Met and MAPK: Functional implications for disease-associated glycosylation changes, Glycobiology 16, 594-601, 2006.

117. S. A. Khan, A. C. Cook, M. Kappil, U. Gunthert, A. F. Chambers, A. B. Tuck, and D. T. Denhardt, Enhanced cell surface CD44 variant (v6, v9) expression by osteopontin in breast cancer epithelial cells facilitates tumor migration: Novel post-transcriptional, post-translational regulation, Clin. Exp. Metastasis 22, 663-673, 2005.

118. S. C. Hong, J. Y. Song, J. K. Lee, N. W Lee, S. H. Kirn, B. W. Yeom, and K. W Lee, Significance of CD44v6 expression in gynecologic malignancies, J. Obstet. Gynaecol. Res. 32, 379-386, 2006.

119. Y. J. Liu, P. S. Yan, J. Li, and J. F. Jia, Expression and significance of CD44s, CD44v6, and nm23 mRNA in human cancer. World J. Gastroenterol. 11, 6601-6606, 2005.

120. N. Ohta, H. Saito, T. Kuzumaki, T. Takahashi, M. M. Ito, T. Saito, K. Nakahara, and M. Hiroi, Expression of CD44 in human cumulus and mural granulosa cells of individual patients in in-vitro fertilization programmes, Mol. Hum. Reprod. 5, 22-28, 1999.

121. H. S. Berner, B. Davidson, A. Berner, B. Risberg, and J. M. Nesland, Differential expression of CD44s and CD44v3-10 in adenocarcinoma cells and reactive mesothelial cells in effusions, Virchows Arch. 436, 330-335, 2000.

122. H. S. Berner, B. Davidson, A. Berner, B. Risberg, G. B. Kristensen, C. G. Trope, G. Van de Putte, and J. M. Nesland, Expression of CD44 in effusions of patients diagnosed with serous ovarian carcinoma-Diagnostic and prognostic implications, Clin. Exp. Metastasis 18, 197-202, 2000.

123. E. P. Reategui, A. A. de Mayolo, P. M. Das, EC. Astor, R. Singal, K. L. Hamilton, W. J. Goodwin, K. L. Carraway, and E. J. Franzmann, Characterization of CD44v3-containing isoforms in head and neck cancer. Cancer Biol. Ther. 5, 1163-1168, 2006.

124. K. Wong, U. Rubenthiran, and S. Jothy, Motility of colon cancer cells: Modulation by CD44 isoform expression, Exp. Mol. Pathol. 75, 124-130, 2003.

125. L. N. Lee, S. H. Kuo, Y. C. Lee, Y. L. Chang, H. C. Chang, I. S. Jan, and PC. Yang, CD44 splicing pattern is associated with disease progression in pulmonary adenocarcinoma, J. Formos. Med. Assoc. 104, 541-548, 2005.

126. U. Protin, T. Schweighoffer, W. Jochum, and F. Hilberg, CD44-deficient mice develop normally with changes in subpopulations and recirculation of lymphocytes subsets, J. Immunol. 163, 4917-4923, 1999.

127. G. Kaya, I. Rodriguez, J. L. Jorcano, P. Vassalli, and I. Stamenkovic, Selective suppression of CD44 in keratinocytes of mice bearing an antisense CD44 transgene driven by a tissue-specific promoter disrupts hyaluronate metabolism in the skin and impairs keratinocyte proliferation, Genes Dev. 11, 996-1007, 1997.

128. S. Nedvetzki, E. Gonen, N. Assayag, R. Reich, R. O. Williams, R. L. Thurmond, J. F. Huang, B. A. Neudecker, F. S. Wang, E. A. Turley, and D. Naor, RHAMM, a receptor for hyaluronan-mediated motility, compensates for CD44 in inflamed CD44-knockout mice: A different interpretation of redundancy, Proc. Natl. Acad. Sci. USA 101, 1808118086, 2004.

129. S. Banerji, J. Ni, S. X. Wang, S. Clasper, J. Su, R. Tammi, M. Jones, and D. G. Jackson, LYVE-1, a new homologue of the CD44 glycoprotein, is a lymph-specific receptor for hyaluronan, J. Cell Biol. 144, 789-801, 1999.

130. R. Prevo, S. Banerji, D. J. P. Ferguson, S. Clasper, and D. G. Jackson, Mouse LYVE-1 is an endocytic receptor for hyaluronan in lymphatic endothelium, J. Biol. Chem. 276, 19420-19430, 2001.

131. J. S. Bonifacino and B. C. Dell'Angelica, Molecular bases for the recognition of tyrosine-based sorting signals, J. Cell Biol. 145, 923-926, 1999.

132. K. G. Rothberg, J. E. Heuser, W. C. Donzell, Y. S. Ying, J. R. Glenney, and R. G. Anderson, Caveolin, a protein component of caveolae membrane coats. Cell 68, 673-682, 1992. 
133. C. M. Carreira, S. M. Nasser, E. di Tomaso, T. P. Padera, Y. Boucher, S. I. Tomarev, and R. K. Jain, LYVE-1 is not restricted to the lymph vessels: Expression in normal liver blood sinusoids and down-regulation in human liver cancer and cirrhosis. Cancer Res. 61, 8079-8084, 2001.

134. C. Cursiefen, L. Chen, L. P. Borges, D. Jackson, J. Cao, C. Radziejewski, P. A. DAmore, M. R. Dana, S. J. Wiegand, and J. W. Streilein, VEGF-A stimulates lymphangiogenesis and hemangiogenesis in inflammatory neovascularization via macrophage recruitment, J. Clin. Invest. 113, 1040-1050, 2004.

135. C. Cursiefen, S. Ikeda, P. M. Nishina, R. S. Smith, A. Ikeda, D. Jackson, J. S. Mo, L. Chen, M. R. Dana, B. Pytowski, RE. Kruse, and J. W. Streilein, Spontaneous corneal hem- and lymphangiogenesis in mice with destrin-mutation depend on VEGFR3 signaling. Am. J. Pathol. 166, 1367-1377, 2005.

136. P. Bono, V. M. Wasenius, P. Heikkila, J. Lundin, D. G. Jackson, and H. Joensuu, High LYVE-1-positive lymphatic vessel numbers are associated with poor outcome in breast cancer, Clin. Cancer Res. 10, 7144-7149, 2004.

137. L. Trojan, M. S. Michel, F. Rensch, D. G. Jackson, P. Alken, and R. Grobholz, Lymph and blood vessel architecture in benign and malignant prostatic tissue: Lack of lymphangiogenesis in prostate carcinoma assessed with novel lymphatic marker lymphatic vessel endothelial hyaluronan receptor (LYVE-1), J. Urol. 172, 103-107, 2004.

138. G. H. Cunnick, W. G. Jiang, K. F. Gomez, and R. E. Mansel, Lymphangiogenesis and breast cancer metastasis, Histol. Histopathol. 17, 863-870, 2002.

139. S. S. Sundar, H. Zhang, P. Brown, S. Manek, C. Han, K. Kaur, M. F. Charnock, D. Jackson, and T. S. Ganesan, Role of lymphangiogenesis in epithelial ovarian cancer, Br. J. Cancer 94, 1650-1657, 2006.

140. F. Gao, Y. M. Lu, M. L. Cao, Y. W. Liu, Y. Q. He, and Y. Wang, Expression and quantification of LYVE-1 in human colorectal cancer, Clin. Exp. Med. 6, 65-71, 2006.

141. D. G. Jackson, Hyaluronan and lymphedema, Lymphology 37, 1-5, 2004.

142. W. R. Jones, C. C. O’Morchoe, H. M. Jarosz, and P. J. O’Morchoe, Distribution of charged sites on lymphatic endothelium, Lymphology 19, 5-14, 1986.

143. J. R. E. Fraser, T. C. Laurent, A. Engstrom-Laurent, and U. B. G. Laurent, Elimination of hyaluronic acid from the blood stream in the human, Clin. Exp. Pharmacol. Physiol. 11, 17-25, 1984.

144. T. C. Laurent and J. R. E. Fraser, The properties and turnover of hyaluronan, Ciba Found. Symp. 124, 9-29, 1986.

145. J. R. E. Fraser, L.-E. Appelgren, and T. C. Laurent, Tissue uptake of circulating hyaluronic acid. Cell Tissue Res. 233, 285-293, 1983.

146. J. R. E. Fraser, T. C. Laurent, H. Pertoft, and E. Baxter, Plasma clearance, tissue distribution and metabolism of hyaluronic acid injected intravenously in the rabbit, Biochem. J. 200, 415-424, 1981.

147. T. C. Laurent, I. M. S. Dahl, L. B. Dahl, A. Engstrom-Laurent, S. Eriksson, J. R. E. Fraser, K. A. Granath, C. Laurent, U. B. G. Laurent, K. Lilja, H. Pertoft, B. Smedsrod, A. Tengblad, and O. Wik, The catabolic fate of hyaluronic acid. Connect. Tissue Res. 15, 33-41, 1986.

148. B. Zhou, J. A. Oka, A. Singh, and P. H. Weigel, Purification and subunit characterization of the rat liver endocytic hyaluronan receptor, J. Biol. Chem. 274, 33831-33834, 1999.

149. B. Zhou, J. A. Weigel, L. A. Fauss, and P. H. Weigel, Identification of the hyaluronan receptor for endocytosis (HARE), J. Biol. Chem. 275, 37733-37741, 2000.

150. B. Zhou, C. T. McGary, J. A. Weigel, A. Saxena, and P. H. Weigel, Purification and molecular identification of the human hyaluronan receptor for endocytosis, Glycobiology 13, 339-349, 2003.

151. B. Zhou, J. A. Weigel, A. Saxena, and P. H. Weigel, Molecular cloning and functional expression of the rat 175kDa hyaluronan receptor for endocytosis, Mol. Biol. Cell 13, 2853-2868, 2002.

152. E. N. Harris, J. A. Weigel, and P. H. Weigel, Endocytic function, glycosaminoglycan specificity, and antibody sensitivity of the recombinant human 190 kDa HA receptor for endocytosis (HARE), J. Biol. Chem. 279, 36201-36209, 2004.

153. O. Politz, A. Gratchev, P. A. G. McCourt, K. Schledzewski, P. Guillot, S. Johansson, G. Svineng, P. Franke, C. Kannicht, J. Kzhyshkowska, P. Longati, F. W. Velten, and S. Goerdt, Stabilin-1 and -2 constitute a novel family of fasciclin-like hyaluronan receptor homologues, Biochem. J. 362, 155-164, 2002.

154. E. N. Harris, S. Kyosseva, J. A. Weigel, and P. H. Weigel, Expression, processing and glycosaminoglycan binding activity of the recombinant human 315-kDa HA receptor for endocytosis (HARE), J. Biol. Chem. 282, 2785-2797, 2006.

155. Y. Tamura, H. Adachi, J. Osuga, K. Ohashi, N. Yahagi, M. Sekiya, H. Okazaki, S. Tomita, Y. lizuka, H. Shimano, R. Nagai, S. Kimura, M. Tsujimoto, and S. Ishibashi, FEEL-1 and FEEL-2 are endocytic receptors for advanced glycation end products, J. Biol. Chem. 278, 12613-12617, 2003. 
156. H. Adachi and M. Tsujimoto, FEEL-1, a novel scavenger receptor with in vitro bacteria-binding and angiogenesismodulating activities, J. Biol. Chem. 277, 34264-34270, 2002.

157. B. Smedsrod, S. Johansson, and S. Goerdt, Shooting HARE, Glycobiology 13, 11G-12G, 2003.

158. M. Falkowski, K. Schledzewski, B. Hansen, and S. Goerdt, Expression of stabilin-2, a novel fasciclin-like hyaluronan receptor protein, in murine sinusoidal endothelia, avascular, tissues, and at solid/liquid interfaces, Histochem. Cell Biol. 120, 361-369, 2003.

159. A. Lindsley, W. Li, J. Wang, N. Maeda, R. Rogers, and S. J. Conway, Comparison of the four mouse fasciclin-containing genes expression patterns during valvuloseptal morphogenesis. Gene Exp. Patterns 5, 593-600, 2005.

160. R. H. Raja, C. T. McGary, and P. H. Weigel, Affinity and distribution of surface and intracellular hyaluronic acid receptors in isolated rat liver endothelial cells, J. Biol. Chem. 263, 16661-16668, 1988.

161. J. Yannariello-Brown, S. J. Frost, and P. H. Weigel, Identification of the $\mathrm{Ca}^{2+}$-independent endocytic hyaluronan receptor in rat liver sinusoidal endothelial cells using a photoaffinity cross-linking reagent, J. Biol. Chem. 267, 20451-20456, 1992.

162. C. T. McGary, R. H. Raja, and P. H. Weigel, Endocytosis of hyaluronic acid by rat liver endothelial cells: Evidence for receptor recycling, Biochem. J. 257, 875-884, 1989.

163. B. Hansen, P. Longati, K. Elvevold, G.-I. Nedredal, K. Schledzewski, R. Olsen, M. Falkowski, J. Kzhyshkowska, F. Carlsson, S. Johansson, B. Smedsrod, S. Goerdt, S. Johansson, and P. McCourt, Stabilin-1 and stabilin-2 are both directed into the early endocytic pathway in hepatic sinusoidal endothelium via interactions with clathrin/AP-2, independent of ligand binding, Exp. Cell Res. 303, 160-173, 2005.

164. R. H. Raja, M. Herzig, M. Grissom, and P. H. Weigel, Preparation and use of synthetic cell culture surfaces. A new reagent for the covalent immobilization of proteins and glycoproteins on a nonionic inert matrix, J. Biol. Chem. 261, 8505-8513, 1986.

165. B. Smedsrod, L. Kjellen, and H. Pertoft, Endocytosis and degradation of chondroitin sulphate by liver endothelial cells, Biochem. J. 229, 63-71, 1985.

166. I. Oynebraten, B. Hansen, B. Smedsrod, and L. Uhlin-Hansen, Serglycin secreted by leukocytes is efficiently eliminated from the circulation by sinusoidal scavenger endothelial cells in the liver, J. Leukoc. Biol. 67, 183-188, 2000.

167. B. Falkowska-Hansen, I. Oynebraten, L. Uhlin-Hansen, and B. Smedsrod, Endocytosis and degradation of serglycin in liver sinusoidal endothelial cells, Mol. Cell Biochem. 287, 43-52, 2006.

168. D. H. Bernanke and R. R. Markwald, Effects of two glycosaminoglycans on seeding of cardiac cushion tissue cells into a collagen-lattice culture system, Anat. Rec. 210, 25-31, 1984.

169. S. L. Shyng, S. Lehmann, K. L. Moulder, and D. A. Harris, Sulfated glycans stimulate endocytosis of the cellular isoform of the prion protein, PrPC in cultured cells, J. Biol. Chem. 270, 30221-30229, 1995.

170. J. A. Schroeder, L. F. Jackson, D. C. Lee, and T. D. Camenisch, Form and function of developing heart valves: Coordination by extracellular matrix and growth factor signaling, J. Mol. Mod. 81, 392-403, 2003.

171. K. J. Grande-Allen, W. J. Mako, A. Calabro, Y. Shi, N. B. Ratliff, and I. Vesely, Loss of chondroitin 6-sulfate and hyaluronan from failed porcine bioprosthetic valves, J. Biomed. Mater. Res. 65A, 251-259, 2003.

172. E. N. Harris and P. H. Weigel, The ligand-binding profile of HARE/Stabilin-2: Hyaluronan and chondroitin sulfates A, C, and D bind to overlapping sites distinct from the sites for heparin, acetylated low-density lipoprotein, dermatan sulfate, and CS-E, Glycobiology Epub. May 22, 2008.

173. E. N. Harris, J. A. Weigel, and P. H. Weigel, The human hyaluronan receptor for endocytosis (HARE) is a systemic clearance receptor for heparin, J. Biol. Chem. 283, Epub. April 22, 2008.

174. M. S. Pandey, E. N. Harris, J. A. Weigel, and P. H. Weigel, The cytoplasmic domain of the hyaluronan receptor for endocytosis (HARE) contains multiple endocytic motifs targeting coated pit mediated internalization, J. Biol. Chem. 283, in press, 2008. 